\title{
Six1 homeoprotein drives myofiber type IIA specialization in soleus muscle
}

\author{
Iori Sakakibara ${ }^{1,2,3,4}$, Maud Wurmser ${ }^{1,2,3}$, Matthieu Dos Santos ${ }^{1,2,3}$, Marc Santolini ${ }^{5}$, Serge Ducommun ${ }^{6}$, \\ Romain Davaze $e^{1,2,3}$, Anthony Guernec ${ }^{1,2,3}$, Kei Sakamoto ${ }^{6}$ and Pascal Maire ${ }^{1,2,3^{*}}$ (i)
}

\begin{abstract}
Background: Adult skeletal muscles are composed of slow and fast myofiber subtypes which each express selective genes required for their specific contractile and metabolic activity. Six homeoproteins are transcription factors regulating muscle cell fate through activation of myogenic regulatory factors and driving fast-type gene expression during embryogenesis.
\end{abstract}

Results: We show here that Six 1 protein accumulates more robustly in the nuclei of adult fast-type muscles than in adult slow-type muscles, this specific enrichment takes place during perinatal growth. Deletion of Six 1 in soleus impaired fast-type myofiber specialization during perinatal development, resulting in a slow phenotype and a complete lack of Myosin heavy chain 2A (MyHCIIA) expression. Global transcriptomic analysis of wild-type and Six1 mutant myofibers identified the gene networks controlled by Six 1 in adult soleus muscle. This analysis showed that Six 1 is required for the expression of numerous genes encoding fast-type sarcomeric proteins, glycolytic enzymes and controlling intracellular calcium homeostasis. Parvalbumin, a key player of calcium buffering, in particular, is a direct target of Six 1 in the adult myofiber.

Conclusions: This analysis revealed that Six 1 controls distinct aspects of adult muscle physiology in vivo, and acts as a main determinant of fast-fiber type acquisition and maintenance.

Keywords: Six1, Myosin heavy chain, Skeletal muscle, Slow and fast myofibers, Soleus, Pvalb

Abbreviations: Aldh1a1, Aldehyde dehydrogenase family 1, subfamily A1; Aldoa, Aldolase A, fructose-bisphosphate; ANOVA, Analysis of variance; Atp2a1, ATPase, $\mathrm{Ca}^{++}$transporting, cardiac muscle, fast twitch 1; Atp2a2, ATPase, $\mathrm{Ca}^{++}$ transporting, cardiac muscle, slow twitch 2; Baf60c, Brahma-associated factor 60c; Chnrg, Cholinergic receptor, nicotinic, gamma polypeptide; Cidea, Cell death-inducing DNA fragmentation factor, alpha subunit-like effector A;

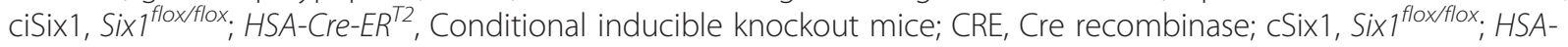
Cre, Human skeletal actin-CRE conditional knockout mice; Ctrl, Control mice; Ddit4l, DNA-damage-inducible transcript 4-like; EDL, Extensor digitorum longus muscle; EMSA, Electrophoretic mobility shift assay; Eno3, Enolase 3, beta muscle; Esr1, Estrogen receptor 1 (alpha); Eya1, EYA transcriptional coactivator and phosphatase 1; Gck, Glucokinase; GP, Gastrocnemius plantaris muscle; GPDH, Glycerophosphate dehydrogenase; Hdac, Histone deacetylase; HSA, Human skeletal actin promoter; Ldha, Lactate dehydrogenase A; MCIP1, Myocyte-enriched calcineurin-interacting protein-1; MEF2, Myocyte enhancer factor 2; MEF3, Myocyte enhancer factor 3; MRFs, Myogenic regulatory factors; Mybpc2, Myosin binding protein C, fast-type; Myh, Myosin heavy chain; MyHC, Myosin heavy chain; Mylpf, Myosin light chain, phosphorylatable, fast skeletal muscle; Myoz1, Myozenin 1; NFAT, Nuclear factor of activated T cells; Nuak1, NUAK family, SNF1-like kinase, 1; PBS, Phosphate buffered saline; (Continued on next page)

\footnotetext{
* Correspondence: pascal.maire@inserm.fr

${ }^{1}$ INSERM U1016, Institut Cochin, Paris 75014, France

${ }^{2}$ CNRS UMR 8104, Paris 75014, France

Full list of author information is available at the end of the article
} 


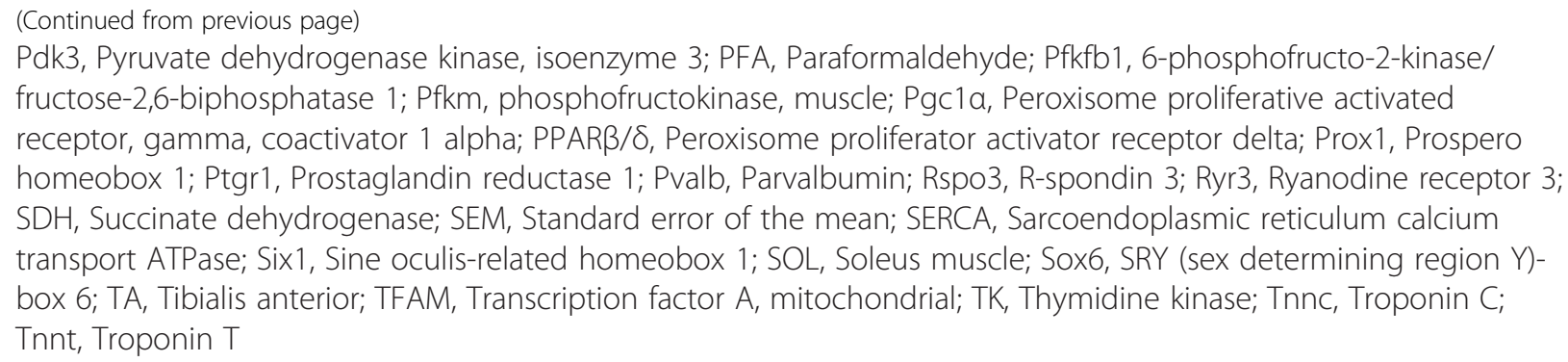

\section{Background}

Adult skeletal muscles are composed of slow and fast myofiber types, and each skeletal muscle is composed of a stereotyped percentage of myofibers of different subtypes. Myofiber types are characterized by the expression of slow- or fast-type sarcomeric proteins and specific $\mathrm{Ca}^{2+}$-handling proteins that modulate its intracellular concentration during the excitation/contraction/relaxation cycle, by their glycolytic and mitochondrial oxidative metabolic properties as well as by their myoglobin content [1-4]. More specifically, the formation of slow or fast sarcomeric units is achieved by the expression of fiber-type specific isoforms of sarcomeric genes such as myosin heavy chain (MyHCI, MyHCIIA, MyHCIIX, $M y H C I I B)$, troponin C (Tnnc1, Tnnc2), troponin I (Tnni1, Tnni2), and troponin $\mathrm{T}$ (Tnnt1, Tnnt3). Their metabolic properties are determined by glycolytic enzymes (Gck, Aldoa, Pfkm, Pfkfb1, Eno3) and by mitochondrial oxidative enzymes [5]. Upon motoneuron firing, stimulation intramyofibrillar $\mathrm{Ca}^{2+}$ is released from the sarcoplasmic reticulum to trigger muscle contraction through its binding to troponin $\mathrm{C}$, and further activation of myosin heavy chain ATPase. The cytosolic $\mathrm{Ca}^{2+}$ reuptake is carried out by the sarcoplasmic reticulum SERCA proteins encoded by slow-type Atp $2 a 2$ and fasttype Atp2a1 [1-4]. SERCA activity is regulated by sarcolipin $(S \ln )$, expressed in slow and fast oxidative fibers, by phospholamban $(P l n)$ and by myoregulin $(M l n)$ expressed in fast fibers, known repressors of SERCA activity $[6,7]$ through binding to SERCA proteins [8-10]. In fast-type fibers, parvalbumin (Pvalb), a $\mathrm{Ca}^{2+}$ buffering protein, removes $\mathrm{Ca}^{2+}$ efficiently from the cytosol to promote relaxation of the myofiber [11].

In adult skeletal muscle, the expression of fiber typespecific genes is coordinated by transcription factors whose activity is modulated by cascades of signaling pathways connected with the environment; mainly by $\mathrm{Ca}^{2+}$ flux induced by motoneuron stimulation, $\mathrm{O}_{2}$, hormones and nutrients availability. Slow motoneuron firing leads to sustained low amplitude elevation in intramyofibrillar calcium concentrations able to activate calcineurin, and CamK while fast motoneuron firing leads to brief intramyofibrillar calcium transients of high amplitude that do not activate calcineurin [12, 13]. Activated calcineurin and CaMK increase the activity of NFAT and MEF2 transcription factors leading to slow sarcomeric gene expression [14, 15]. Muscle mitochondrial oxidation activity which is increased during exercise is under the control of $\mathrm{PPAR} \beta / \delta$ and PGC1 $\alpha$ and PGC1 $\beta$, two transcriptional coactivators of PPAR $\beta / \delta$ and activators of oxidative metabolism [16-18]. Whereas muscle specific deletion of both PGC1 $\alpha$ and PGC1 $\beta$ does not change muscle fiber type [19], muscle-specific deletion of PPAR $\beta / \delta$ leads to an increased number of fast fibers with reduced oxidative capacity [20], while PPAR $\beta / \delta$ ectopic expression in adult myofibers can change both myosin heavy chain content and oxidative metabolism [21]. Upstream regulators controlling fast myofiber phenotypes are HDACs, Sox6 and Linc-Myh known to suppress slow-type gene expression in fast myofibers [15, 22-25], MyoD [26] and Six1 $[25,27]$. Hifl $\alpha$ regulates the expression of genes coding for enzymes of the glycolysis pathway, but its deletion does not lead to major modification of the expression of fiber-type specific sarcomeric proteins while it impairs metabolic adaptation upon exercise [28]. Little is known however concerning the importance of these fiber-type regulators in the coordinated expression of slow or fast genes during perinatal development, the period when muscle fiber specialization takes place [1, 2]. In particular, the mechanisms presiding at the expression of a single fast Myh gene in hundreds nuclei of a myofiber have not yet been elucidated $[25,29,30]$.

Six homeoproteins are major myogenic transcription factors that directly bind to DNA sequences called MEF3s to control embryonic myogenesis [31-34] and genesis of fast-type myofibers [29, 35]. Forced expression of Six1 and its Eya1 cofactor in adult slow myofibers can reprogram adult slow-twitch oxidative fibers toward a fast-twitch glycolytic phenotype [31]. In adult fast-type skeletal muscles, Six1 directly regulates the expression of numerous fast-type muscle genes [25]. Furthermore, Six1 interacts with the central enhancer of the Myh fast genes locus, and controls the expression of the fast-type Myh genes (MyHCIIA, MyHCIIX, MyHCIIB) [25].

While Six1 has been detected in soleus (SOL) muscle at the mRNA and protein levels, its physiological role in 
slow-type muscles has not been explored [25]. Mouse C57bl6N SOL is classified as a slow-type skeletal muscle, composed of approximately $60 \%$ of slow-type/oxydative myofibers and $40 \%$ of fast-type/oxydative myofibers. In this study, we analyzed the phenotypic consequences of Six1 loss in SOL myofibers during mouse perinatal development and in adult. We show that Six1 governs the specification of fast MyHCIIA myofibers and is required for the maintenance of $M y H C I I A$ expression.

\section{Methods}

\section{Animals and ethics statement}

Animal experimentation was carried out in strict accordance with the European convention STE 123 and the French national charter on the Ethics of Animal Experimentation. Protocols were approved by the Ethical Committee of Animal Experiments of the Institut Cochin, CNRS UMR 8104, INSERM U1016. Surgery was performed under ketamine/xylazine anesthesia, and all efforts were made to minimize suffering. Six $1^{\text {flox/flox }}$; $H S A-C r e$ conditional knockout mice $(c \operatorname{Six} 1 \mathrm{KO})$ were obtained by breeding the Six1-LoxP mice and transgenic mice expressing a CRE recombinase under the control of the human skeletal actin promoter (HSA) [20]. Six1flox/flox; HSA-Cre-ER ${ }^{T 2}$ conditional inducible knockout mice (ciSix1 KO) were obtained by breeding the Six1LoxP mice and HSA-CRE-ER ${ }^{T 2}$ mice [36]. two-monthold ciSix $1 \mathrm{KO}$ males were given intraperitoneal injection of tamoxifen (1 mg per mouse per day; Sigma) for five consecutive days.

\section{Immunohistochemistry}

For Six1 immunostaining, SOL and gastrocnemius plantaris (GP) muscles were embedded in cryomatrix and quickly frozen in isopentane cooled with liquid nitrogen. Cryostat sections $(10 \mu \mathrm{m})$ were fixed in $4 \%$ PFA and washed in $1 \times$ PBS. The sections were treated with Antigen Unmasking Solution (H-3300, Vector Laboratories) at $95{ }^{\circ} \mathrm{C}$ for $10 \mathrm{~min}$ and washed in $1 \times$ PBS for three times. Sections were treated with $1 \% \mathrm{H}_{2} \mathrm{O}_{2}$ solution for $20 \mathrm{~min}$. After three washes in $1 \times$ PBS, they were permeabilized with $0.1 \%$ Triton X-100 for $20 \mathrm{~min}$ and left for $1 \mathrm{~h}$ in blocking solution (1× PBS, $1.5 \%$ goat serum, $0.1 \%$ Triton X-100). Rabbit polyclonal antibodies directed against Six1 (HPA001893, Sigma) (1/100 dilution), and dystrophin (NCL-DYS2, Leica Biosystems) (1/50 dilution) were applied overnight at $4{ }^{\circ} \mathrm{C}$ to the treated sections. The next day, after three washes with $1 \times$ PBS containing $0.05 \%$ Tween-20, sections were incubated for $1 \mathrm{~h}$ with appropriate fluorescent secondary antibodies (Alexa Fluor 594 goat anti-mouse IgG 1/1000 dilution, Invitrogen) and biotynilated secondary antibodies (anti-rabbit IgG 1/200, Vector Laboratories). After three washes with $1 \times$ PBS containing $0.05 \%$
Tween-20, samples were incubated in VECTASTAIN Elite ABC Reagent (Vector Laboratories) for $30 \mathrm{~min}$. After three washes with $1 \times$ PBS containing $0.05 \%$ Tween-20, samples were incubated with a tyramide solution labeled by Alexa Fluor 488 (Tyramide Signal Amplification kit, invitrogen). After three washes with $1 \times$ PBS containing $0.05 \%$ Tween-20, samples were mounted in Vectashield mounting medium.

For determination of Myh isoform expression, SOL and GP muscles were embedded in cryomatrix and quickly frozen in isopentane cooled with liquid nitrogen. Cryostat sections $(10 \mu \mathrm{m})$ were washed in PBS, permeabilized with $0.1 \%$ Triton X-100 for $20 \mathrm{~min}$ and left for $1 \mathrm{~h}$ in blocking solution ( $1 \times$ PBS, $1.5 \%$ goat serum, $0.1 \%$ Triton X-100). Rabbit poly-clonal antibodies directed against Laminin (Z0097, Dako) (1/100 dilution), and mouse monoclonal antibodies against $\mathrm{MyHCI}$ (NOQ7.5.4D, Sigma) (1/1000 dilution), MyHCIIA (SC-71, Developmental Studies Hybridoma Bank) (1/ 20 dilution), fast $\mathrm{MyHCs}$ (My-32, Sigma) (1/50 dilution) and MyHCemb (F1.652, sc-53091 Santa Cruz Biotechnology, Inc.) (1/20 dilution) were applied overnight at $4{ }^{\circ} \mathrm{C}$ to the treated sections. The next day, after three washes with $1 \times$ PBS containing $0.05 \%$ Tween-20, sections were incubated for $1 \mathrm{~h}$ with appropriate fluorescent secondary antibodies (Alexa Fluor 488 goat anti-rabbit IgG 1/1000 dilution, Alexa Fluor 594 goat antimouse IgG $1 / 1000$ dilution, Invitrogen). After three washes with $1 \times$ PBS containing $0.05 \%$ Tween-20, samples were mounted in Vectashield mounting medium. For fiber type counting, each $\mathrm{MyHC}$ positive fiber was counted in the entire SOL muscle sections, and the number of positive fibers was divided by the total SOL number of fibers.

\section{SDH/GPDH staining}

Fresh-frozen sections were incubated in $0.2 \mathrm{M}$ phosphate buffer ( $\mathrm{pH} 7.6)$ containing sodium succinate and nitroblue tetrazolium, NBT (N6876, Sigma Aldrich) for $30 \mathrm{~min}$ at $37^{\circ} \mathrm{C}$. Sections were then washed with water and mounted in glycerine gelatin medium. GPDH staining was performed by incubation of unfrozen muscle sections with $\alpha$-glycerol phosphate as described [37]. For quantification of SDH and GPDH staining, the color images were converted to thresholded images at hue (121-208) and brightness (0-140) by a threshold tool of Image s software. The area of thresholded images was measured by ImageJ and normalized by the whole soleus muscle area.

\section{RNA preparation}

Soleus muscles were collected from $c \operatorname{Six} 1 \mathrm{KO}$ and control mice. Total RNAs were extracted using Trizol Reagent (Invitrogen) according to manufacturer's instruction. 


\section{CDNA synthesis and qPCR}

RNAs were treated with DNase I (Turbo DNA-free, Invitrogen) and were reverse-transcribed with Superscript III kit (Invitrogen) according to manufacturer's instruction. Reverse transcription was performed with $1 \mu \mathrm{g}$ of total RNA. Quantitative real time PCR (Light Cycler 480, Roche) was performed using Light Cycler 480 SYBR Green I Master Kit (Roche) according to the manufacturer's protocols. PCR was performed for 40 cycles of $95^{\circ}$ $\mathrm{C}$ for $15 \mathrm{~s}, 60^{\circ} \mathrm{C}$ for $15 \mathrm{~s}$, and $72{ }^{\circ} \mathrm{C}$ for $15 \mathrm{~s}$. Gene expression levels were normalized by the expression level of the housekeeping gene Actb. The sequences of the oligonucleotides used in this study are given in Additional file 1: Table S1.

\section{ChIP experiments}

GP and tibialis anterior (TA) muscles of 2 months old female mice were minced with scissors immediately after harvesting and fixed in $1 \%$ formaldehyde for $10 \mathrm{~min}$. Formaldehyde was quenched by addition of $0.125 \mathrm{M}$ glycine, and muscles were washed twice in PBS. Muscles were then incubated on ice in lysis buffer $(10 \mathrm{mM}$ Tris$\mathrm{HCl} \mathrm{pH} \mathrm{7.9,} 85 \mathrm{mM} \mathrm{KCl}, 0.5 \% \mathrm{NP} 40$, protease inhibitors (Complete, Roche)) for $10 \mathrm{~min}$ and homogenized with a mortar and subsequently with a dounce homogenizer. Nuclei were obtained by centrifugation, incubated in SDS lysis buffer $(50 \mathrm{mM}$ Tris- $\mathrm{HCl} \mathrm{pH}$, $10 \mathrm{mM}$ EDTA, $1 \%$ SDS, protease inhibitors) for $10 \mathrm{~min}$, and sonicated in a bioruptor apparatus (Diagenode). The debris was removed by centrifugation. Sonicated DNA was incubated with $1 \mu \mathrm{g}$ of Six 1 antibodies (HPA001893, Sigma) under rotation at $4{ }^{\circ} \mathrm{C}$ overnight. $20 \mu$ of dynabeads protein $\mathrm{G}$ (Invitrogen) were added to the lysates and incubated under rotation at $4{ }^{\circ} \mathrm{C}$ for $1 \mathrm{~h}$. The beads were washed with low-salt buffer ( 2 mM EDTA, $20 \mathrm{mM}$ Tris- $\mathrm{HCl} \mathrm{pH}$ 8, $150 \mathrm{mM} \mathrm{NaCl}, 1 \%$ TritonX-100, $0.1 \%$ SDS), high-salt buffer (2 mM EDTA, $20 \mathrm{mM}$ Tris- $\mathrm{HCl}$ $\mathrm{pH}$ 8, $0.5 \mathrm{M} \mathrm{NaCl}, 1 \%$ TritonX-100, $0.1 \%$ SDS), LiCl buffer (1 mM EDTA, $10 \mathrm{mM}$ Tris- $\mathrm{HCl} \mathrm{pH} 8,0.25 \mathrm{M}$ $\mathrm{LiCl}, 1 \% \mathrm{NP} 40,1 \%$ deoxycholate), and TE buffer (1 mM EDTA, 10 mM Tris-HCl pH 8). DNA was eluted with elution buffer ( $1 \% \mathrm{SDS}, 0.1 \mathrm{M} \mathrm{NaHCO}_{3}$ ) containing $0.1 \mathrm{mg} / \mathrm{ml}$ proteinase $\mathrm{K}$ (Invitrogen) at $62{ }^{\circ} \mathrm{C}$ for $2 \mathrm{~h}$, and proteinase $\mathrm{K}$ was inactivated by incubation at $95{ }^{\circ} \mathrm{C}$ for $10 \mathrm{~min}$. DNA was finally purified with MinElute PCR purification kit (Qiagen). The amount of specific amplified DNA is normalized by input amplification. The sequences of the oligonucleotides used in this study are as follows. Actb, $5^{\prime}$-TGTTACCAACTGGGACGACA-3' and 5'-ACCTGGGTCATCTTTTCACG-3'; PvalbMEF 3_1, 5'-GGAGCCTTTCATGGTGTGAT-3' and 5'-GG CGTGTGAATCACTTTCCT-3'; PvalbMEF3_2, 5'- GG ATGGGGGTGAATGTGATA-3' and 5' - CTTCCGGTG TCAGGTACTCC-3'.

\section{EMSA}

EMSA was carried out with Six1 and Six4 full-length mouse cDNA cloned into the pCR3 vector (Clontech) as previously described [38]. Recombinant mouse Six1 and Six4 proteins were obtained separately with a T7 transcription/translation kit (Promega) and mixed before contact with the DNA. Myogenin MEF3 DNA was incubated with recombinant proteins. Competition experiments were performed in the presence of a tenfold and hundredfold molar excess of unlabeled identified Pvalb MEF3_1, Pvalb MEF3_2, Myogenin MEF3, Myod1DRR MEF3, or Myogenin NFI sites. The sequences of the oligonucleotides used are as follows, the MEF3 consensus sequence is in italic; MyogF $5^{\prime}$-TGG GGG GGC TCA GGT TTC TGT GGC GT-3'. MyogR 5'-ACG CCA CAG AAA CCT GAG CCC CCC CA-3'. NF1F 5'TAT CTC TGG GTT CAT GCC AGC AGG G-3'. NF1R 5'-CCC TGC TGG CAT GAA CCC AGA GAT A-3'. PvalbMEF3_1F, 5' - TGA GCA TCT GTA ACC TGA CCC TTG G -3'. PvalbMEF3_1R, 5' - CCA AGG GTC AGG TTA CAG ATG CT-3'. PvalbMEF3_2F, 5' TGA GTA CCT GAC ACC GGA AGG GGA G-3'. PvalbMEF3_2R, 5'- CTC CCC TTC CGG TGT CAG GTA CT-3'. MyodDRRF, 5' - AGT TGG ATC CGG TTT CCA GAG GC -3'. MyodDRRR, 5' - TGA GAC AGT AAT TTT ATC CTG CT -3'.

\section{Plasmids construction}

For the construction of the pGL3-Pvalb, C57bl6N mouse DNA was first used as a template to clone the $700 \mathrm{bp}$ promoter of Pvalb with forward MluI, 5'- GTAACCTGACCCTTGGAAACCAG $-3^{\prime}$ and reverse BglII, 5'CTTGGATGAGCAGAGGCCGGA-3' primers. This Pvalb promoter fragment was subsequently inserted into an MluI-BglII digested pGL3 basic plasmid. For the construction of the pGL3-PvalbmutMEF3-1, PvalbmutMEF3-2 and PvalbdoublemutMEF3, the two MEF3 sites of the promoter were mutated as follows; Pvalb MEF3-1: 5'GTAACCTGA to 5'CGCGTCTGA; Pvalb MEF3-2: 5'GACACCGGA to 5'CTCGAGGGA. All plasmids sequences were confirmed by sequencing.

\section{Electroporation}

In vivo transfections were also carried out on ten-week old C57Bl6N mice. For each experimental conditions three to five TA muscles belonging to different mice were used. Under isoflurane anesthesia, legs were shaved and muscles were pre-treated by injection of a sterile $0.9 \% \mathrm{NaCl}$ solution containing $0.4 \mathrm{U}$ of bovine hyaluronidase $/ \mu \mathrm{l} 2 \mathrm{~h}$ before plasmid injection. Two micrograms of Luciferase-expressing vector and one hundred ng of pRL-TK vector (Promega) were introduced into TA muscles of ten-week-old mice by electroporation as previously described [27]. Two weeks following electroporation, 
electroporated muscles were frozen in liquid nitrogen before processing for Luciferase assays.

\section{Luciferase assays}

Two weeks after electroporation, TA were dissected and frozen in liquid nitrogen before processing. TA were homogenized in Passive Lysis Buffer (Dual-Luciferase Reporter Assay System, Promega) and rotated for $15 \mathrm{~min}$. The homogenate was centrifuged to remove debris, and the supernatant was used for Luciferase activity measurement according to manufacturer's instruction (Dual-Luciferase Reporter Assay System, Promega).

\section{Microarrays}

After validation of RNA quality with the Bioanalyzer 2100 (using Agilent RNA6000 nano chip kit), 50 ng of total RNA were reverse-transcribed following the Ovation PicoSL WTA System (Nugen). Briefly, the resulting double-strand cDNA was used for amplification based on SPIA technology. After purification according to Nugen protocol, $5 \mu \mathrm{g}$ of single strand DNA was used for generation of Sens Target DNA using Ovation Exon Module kit (Nugen). $2.5 \mu \mathrm{g}$ of Sens Target DNA were fragmented and labelled with biotin using Encore Biotin Module kit (Nugen). After control of fragmentation using Bioanalyzer 2100, the cDNA was then hybridized to GeneChip ${ }^{\circ}$ Mouse Gene 1.0 ST (Affymetrix) at $45{ }^{\circ} \mathrm{C}$ for $17 \mathrm{~h}$. After overnight hybridization, the ChIPs were washed using the fluidic station FS450 following specific protocols (Affymetrix) and scanned using the GCS3000 7G. The scanned images were then analyzed with Expression Console software (Affymetrix) to obtain raw data (cel files) and metrics for quality controls. The analysis of some of these metrics and the study of the distribution of raw data show no outlier experiment. RMA normalization was performed using $\mathrm{R}$ and normalized data was subjected to statistical tests.

\section{Preparation of nuclear and cytosolic proteins}

SOL and GP muscles of 2, 3, and 12 weeks old mice were frozen with liquid nitrogen and were homogenized with a mortar. Homogenates were fractionated by NEPER kit (78833, Thermo Scientific) according to manufacturer's instruction.

\section{Western blot}

Cell or tissue lysates of GP and SOL from $c$ Six $1 \mathrm{KO}$ and control mice $(20-40 \mu \mathrm{g})$ were denatured in Laemmli buffer, separated by SDS-polyacrylamide gel electrophoresis and transferred to nitrocellulose membrane. Membranes were blocked in $50 \mathrm{mM}$ Tris- $\mathrm{HCl} \mathrm{pH} \mathrm{7.6,} 137 \mathrm{mM} \mathrm{NaCl}$ and $0.1 \%(\mathrm{v} / \mathrm{v})$ Tween-20 containing $10 \%(\mathrm{w} / \mathrm{v})$ skimmed milk or $5 \%(\mathrm{w} / \mathrm{v})$ BSA for $1 \mathrm{~h}$ at room temperature and incubated overnight at $4{ }^{\circ} \mathrm{C}$ with the indicated primary antibodies
(Complex I, NADH dehydrogenase, ab14713, Abcam (Cambridge, UK); Complex II, succinate dehydrogenase, ab109865, Abcam (Cambridge, UK); cytochrome bc1 complex, ab110252, Abcam (Cambridge, UK); Complex IV, cytochrome C oxidase, ab14744, Abcam (Cambridge, UK); Complex V, ATP synthase, ab14748, Abcam (Cambridge, UK); hexokinase II, Sc-6521 (Santa Cruz Biotechnology); glycogen synthase 1, CST \#3893, Cell Signaling Technology; AS160, 07-741, Millipore; GLUT4, kind donation from Geoffrey Holman, University of Bath); lamin B, sc-6216 (Santa Cruz Biotechnology); $\beta$-tubulin, 05-661 (Millipore); Six1, HPA001893 (Sigma). Detection was performed using horseradish peroxidase conjugated secondary antibodies and enhanced chemiluminescence reagent.

\section{Statistical analysis}

All graphs represent mean values \pm SEM. Significant differences between mean values were evaluated using twotailed, unpaired Student's $t$ test (when two groups were analyzed) or one-way ANOVA followed by Student Newman-Keuls test (for three or more groups).

\section{Microarray data accession number}

Microarray data have been deposited in the Gene Expression Omnibus as accession no. GSE50023.

\section{Results}

Six 1 protein subcellular localization in adult myofibers

To analyze the properties of Six 1 homeoprotein in adult SOL muscles, we first determined its expression pattern. We showed previously that Six1 mRNA accumulates in both fast and slow muscles and that Six1 protein is produced in both type of muscles but accumulates more robustly in the nuclei of fast myofibers as evaluated by immunohistochemistry [25, 27]. We here show that Six1 protein is produced in the GP (fast gastrocnemius and plantaris muscles) and in the SOL of 2 weeks, 3 weeks and adult mice (Fig. 1a), but that the nuclear accumulation of Six 1 is drastically reduced between 3 weeks and the adult stage in the SOL (Fig. 1b), although no obvious cytoplasmic Six1 accumulation is observed in the SOL as estimated by Western blot experiments. Six 1 protein was further detected in the fast GP and the slow SOL muscles by immunofluorescence using antibodies directed against Six1 at several developmental stages. At embryonic day E18.5, we observed that Six1 is present in the nuclei of myofibers of the GP and SOL expressing at that stage both $\mathrm{MyHCI}(\mathrm{slow} / \beta)$ and fast $\mathrm{MyHC}$ (detected by $\mathrm{My} 32$ antibodies that recognize $\mathrm{MyH}$ Cemb, MyHCneo and adult fast MyHC) (Fig. 1c). On adult sections, Six 1 protein accumulation was detected preferentially in the nuclei of GP as compared with SOL nuclei (Fig. 1d), in agreement with previous results [27]. While GP muscles are mainly composed 


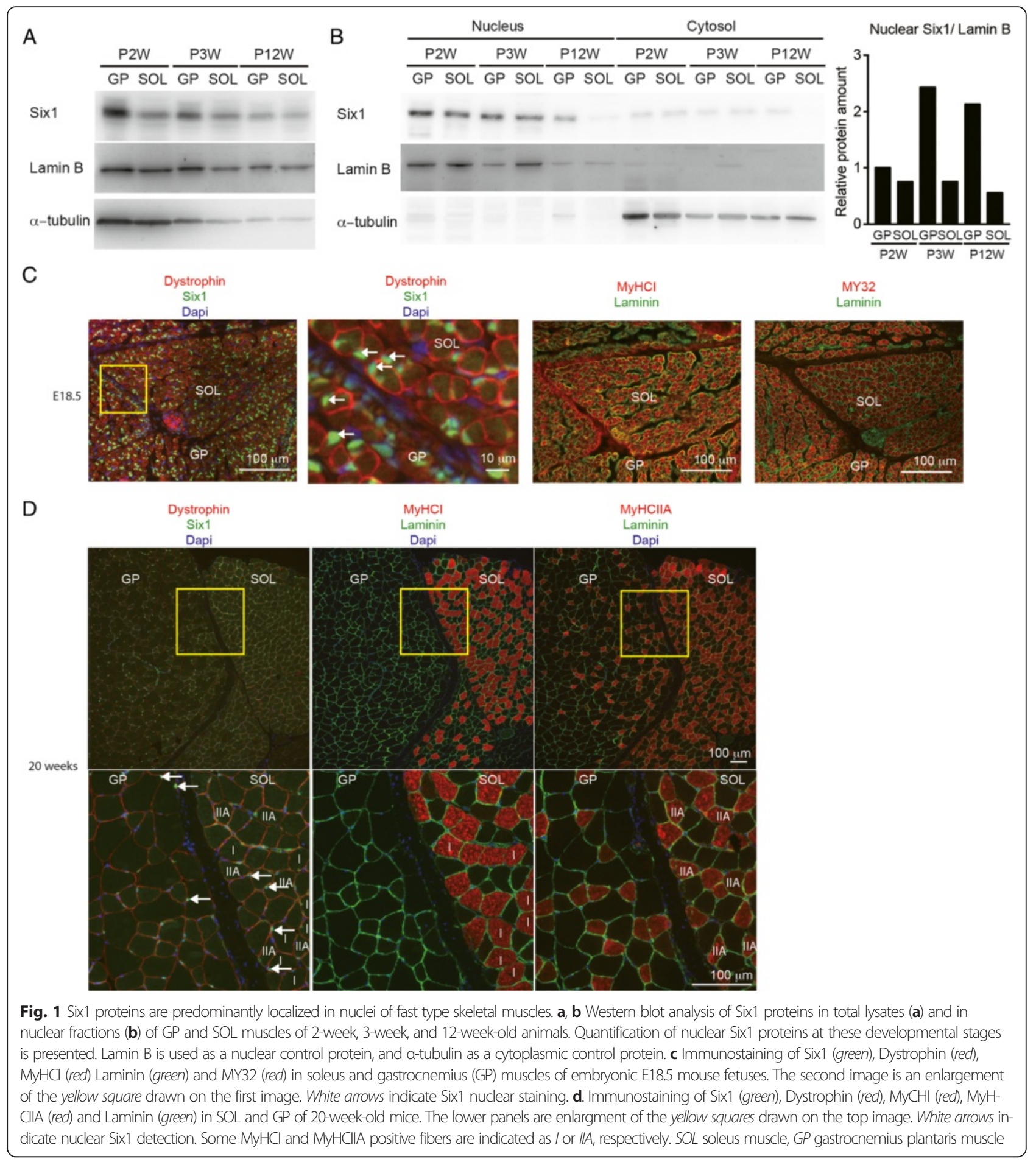

of myofibers expressing MyHCIIB or MyHCIIX, SOL muscles are composed mainly by myofibers expressing $\mathrm{MyHCI}$ (slow/ $\beta$ ), MyHCIIA and by few myofibers expressing MyHCIIX. Nuclear Six1 is nevertheless detected in the SOL in the fast MyHCIIA, and in some $\mathrm{MyHCI}$ fibers (Fig. 1c). These results showed that in adult hindlimb muscles, Six1 proteins accumulate preferentially in the nuclei of GP fast myofibers than in the nuclei of SOL myofibers (Fig. 1c), in accordance with the low amount of Six1 proteins detected in myonuclei of SOL by Western blot analysis (Fig. 1a), and that this preferential nuclear Six1 accumulation takes place during the perinatal period. 


\section{Six 1 deficiency impairs adult muscle fast type phenotype acquisition in SOL}

To characterize the role of Six 1 in adult SOL, we analyzed myofiber-specific Six1 knockout (cSix1 KO) mice [25]. cSix1 KO mice were viable, and Six $1 \mathrm{mRNA}$ and protein were not detectable in adult GP or SOL muscles [25]. As fiber type specialization that leads to the expression of a single $M y h$ gene in all the myonuclei of a given myofiber proceeds during the neonatal stage, we next performed immunohistochemistry to analyze the content of MyHCI, MyHCIIA, and MyHCemb of SOL in 3week-old cSix 1 mutant myofibers. In control (Ctrl) mice, $10 \%$ of myofibers expressed MyHCemb, $50 \%$ expressed MyHCI, and $60 \%$ expressed MyHCIIA (Fig. 2a, b). In cSix1 KO mice, $40 \%$ of myofibers still expressed MyHCemb, $96 \%$ of myofibers expressed MyHCI, and $33 \%$ of myofibers expressed MyHCIIA. This result suggested that sustained expression of Six1 in the perinatal period is important for embryonic to adult fast myofiber transition in SOL and that the decrease of nuclear Six1 accumulation may be important to allow $M y H C I$ exclusive expression in slow-type SOL myofibers. It is known that perinatal muscle growth in mice takes place by accretion of new satellite cells (SC) [39]. As Six1 is expressed in SC [40-42], it is possible that Six1 may be transiently expressed by new accreted myonuclei until P21 [39], before its efficient deletion by the HSA-CRE recombinase only active in post mitotic myofibers. To test this hypothesis, we measured Six1 protein accumulation in the nuclei of SOL at 3 weeks of development and detected Six1 positive myonuclei in cSix 1 SOL at this development stage (Fig. 2e). This showed that HSA-CRE recombinase had not yet recombined the Six 1 flox allele in all P21 myonuclei, allowing Six1 to be detected in some nuclei of perinatal myofibers of mutant animals.

In 12-week-old adult animals, at a stage when Six 1 is no longer detected in adult cSix1 myonuclei [25], $100 \%$ of SOL myofibers in mutant mice expressed $\mathrm{MyHCI}$ while MyHCIIA was not detectable (Fig. 2c, d), contrary to Ctrl SOL where $45 \%$ of myofibers expressed $\mathrm{MyH}-$ CIIA and $55 \%$ expressed MyHCI (Fig. 2c, d). In adult cSix1 mutant SOL, MyHCIIX and MyHCIIA mRNA became undetectable (Fig. 4b), while the amount of MyHCI mRNA increased twice (Fig. 4b).

The number of SOL myofibers present in Ctrl and cSix1 KO was comparable, excluding that absence of MyHCIIA myofibers in adult mutant animals is the consequence of their death (Additional file 2: Figure S1). We observed no significant modification of the CSA between wt and cSix $1 \mathrm{KO}$ adult myofibers, excluding that Six 1 is a main regulator of MyHCIIA myofibers growth in SOL (Additional file 2: Figure S1).

To analyze the oxidative/glycolytic metabolism of mutant SOL muscles, SDH, and GPDH staining were performed on 12-week-old soleus muscle sections (Fig. 3a, b). A twoto threefold decrease of SDH activity was observed in cSix 1 SOL as compared with that of control (Fig. 3a). Nevertheless, no significant difference of mitochondrial protein contents was observed in $c$ Six 1 SOL extracts as determined by Western blots (Fig. 3c). We also observed a robust decrease in GPDH activity in $c$ Six 1 SOL as compared with that of control, suggesting that absence of Six 1 decreases glycolytic flux in adult SOL myofibers (Fig. 3b).

Networks of genes under the control of Six 1 in adult SOL To explore the networks of genes under the control of Six1 in adult SOL, we performed Affymetrix microarray analyses using RNA from adult Ctrl and $c \operatorname{Six} 1 \mathrm{KO}$ mice. Genes whose expression is the most up- or downregulated (Additional file 3: Table S2) are shown as a heat map and as a bar graph (Fig. 4a and Additional file 4: Figure S2). The expression of several fast-type genes is down-regulated in cSix $1 \mathrm{KO}$ including Pvalb, Mybpc2, MyHCIIA, Myl1, Myoz1, and Mylpf (Fig. 4a). We validated the expression of those fiber type-specific genes by qPCR. Consistent with immunohistochemistry data, MyHCIIA mRNA was no longer detectable in SOL of 12-week-old cSix1 KO mice, and MyHCI mRNA level was increased by twofold as compared with control (Fig. 4b). The expression levels of slow-type genes (Tnnt1, Tnni1, Tnnc1) were also increased by twofold in cSix1 KO soleus muscles while the expression of fasttype genes Tnnt3 and Tnni2 was not detected and expression of Tnnc2 was markedly decreased (Fig. 4b). These data show that nuclear accumulation of Six1 observed in SOL MyHCIIA-myofibers is necessary to activate the expression of MyHCIIA and of other fasttype sarcomeric genes and to suppress the expression of $\mathrm{MyHCI}$ and other slow-type muscle genes.

The second most down-regulated gene in $c \operatorname{Six} 1 \mathrm{SOL}$ is Pvalb (Fig. 4a), which is a calcium buffering protein allowing muscle relaxation in fast-type muscles [11, 43-45]. Furthermore, other genes related with calcium regulation were also modified in cSix $1 \mathrm{KO}$ mice (Additional file 4: Figure S2). We validated the down-regulation of Pvalb mRNA level in $c$ Six 1 SOL by qPCR experiments (Fig. 4c). The expression level of $\operatorname{Sln}, A t p 2 a 2$, and Ryr3 was increased in $c$ Six 1 SOL muscles while the expression of fasttype genes Myoz1 and Atp2a1 was strongly decreased (Fig. 4d). These data suggest that Six1 regulates intramyocellular calcium transients through the control of the expression of several fiber type-specific calcium-binding proteins, and suggest a feedback loop between Six1 nuclear accumulation and resting intracellular calcium concentration.

Concerning Affymetrix results, the expression of several genes encoding glycolytic enzymes (Aldoa, Ldha, Pfkfb1, PFKm, and Eno3) was also down-regulated (Fig. 4a and 


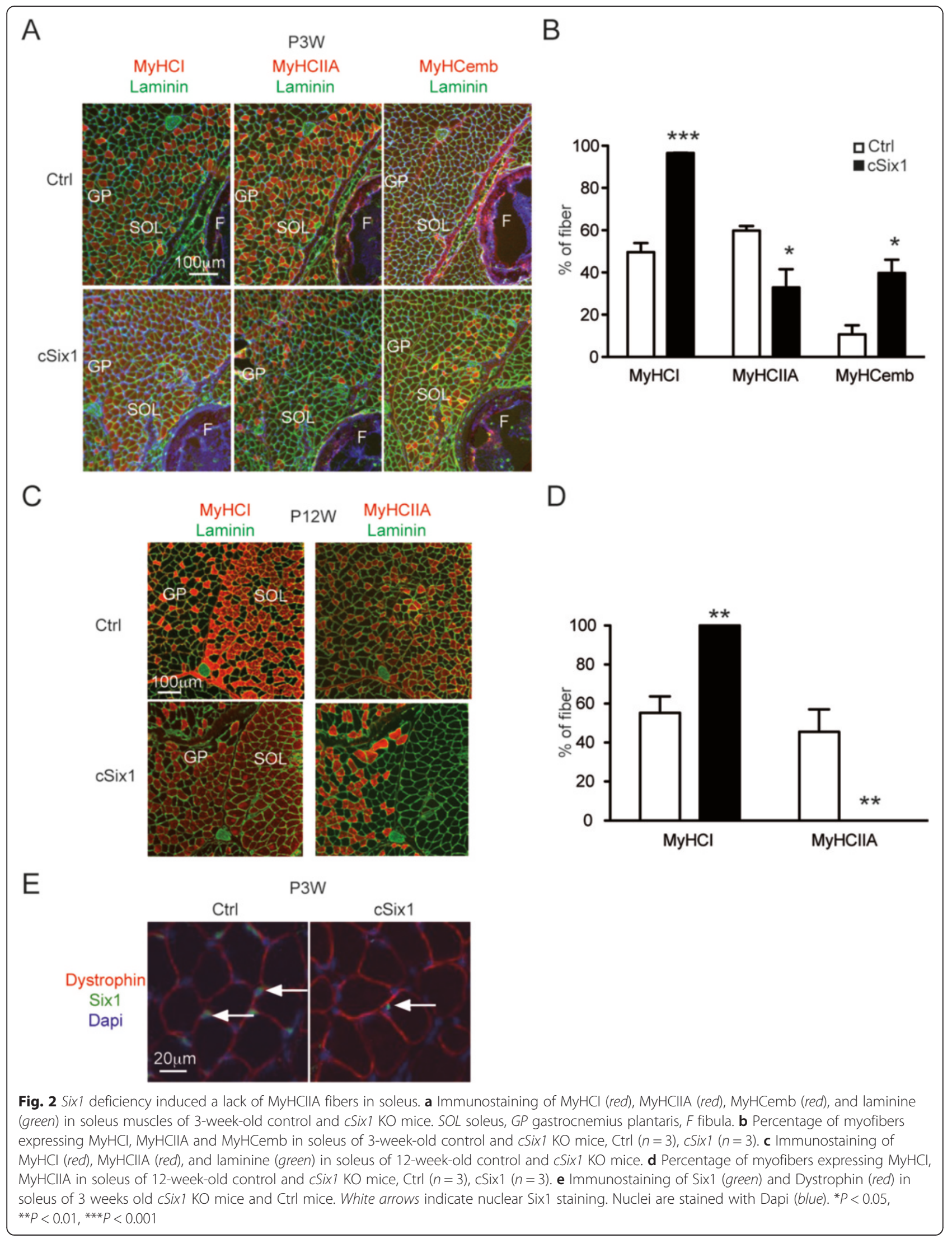




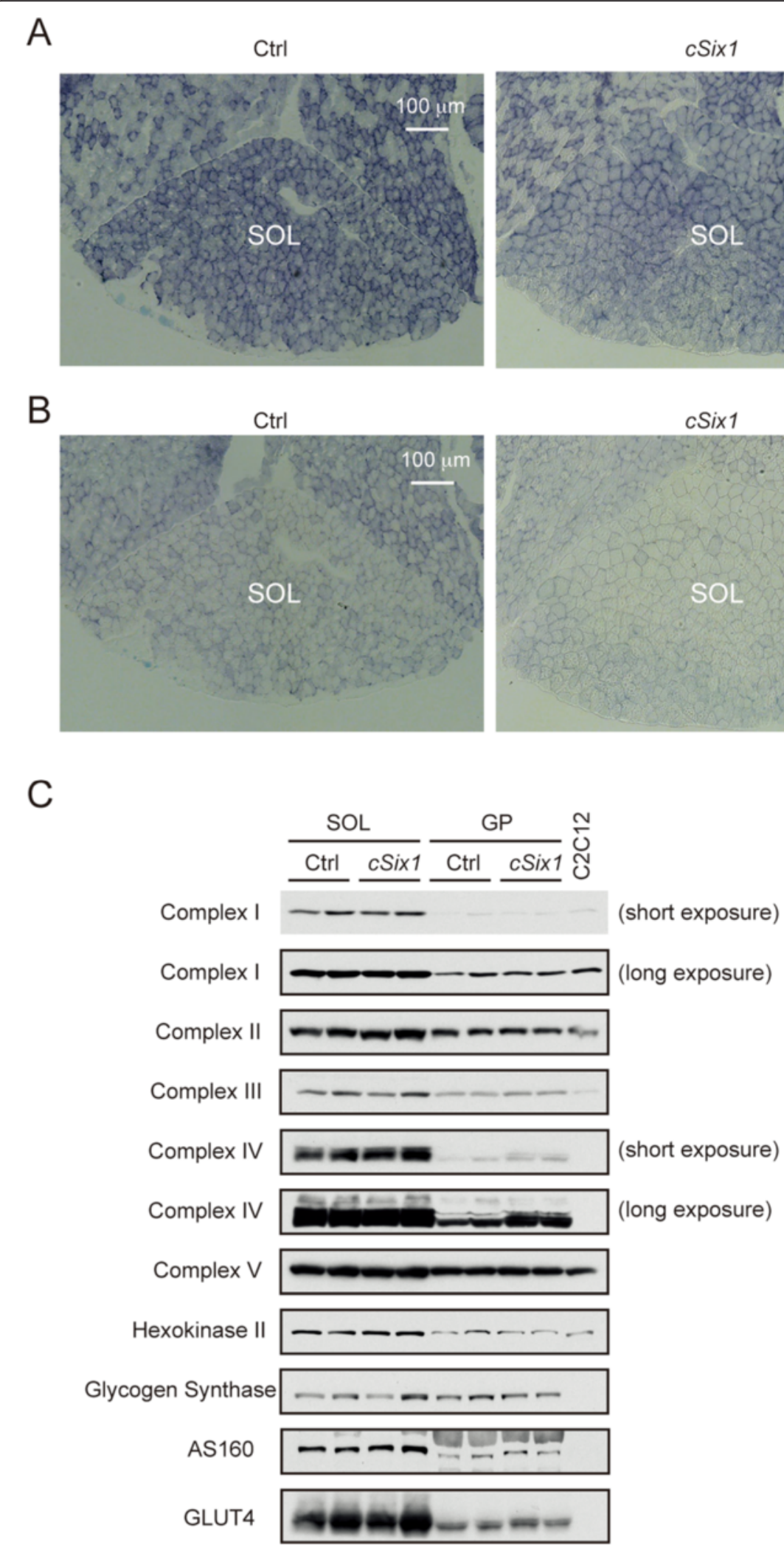

Fig. 3 Metabolic properties of cSix $1 \mathrm{KO}$ muscles. a SDH staining of soleus of 12-week-old cSix $1 \mathrm{KO}$ and wt mice, and percentage of the area of positive fibers. $\mathbf{b}$ GPDH staining of soleus of 12-week-old cSix $1 \mathrm{KO}$ and wt mice, and percentage of the area of positive fibers. c Western blot analysis of mitochondrial proteins and glucose metabolism proteins in SOL and GP of Ctrl and cSix1 KO mice. C2C12, mitochondrial fraction of C2C12 


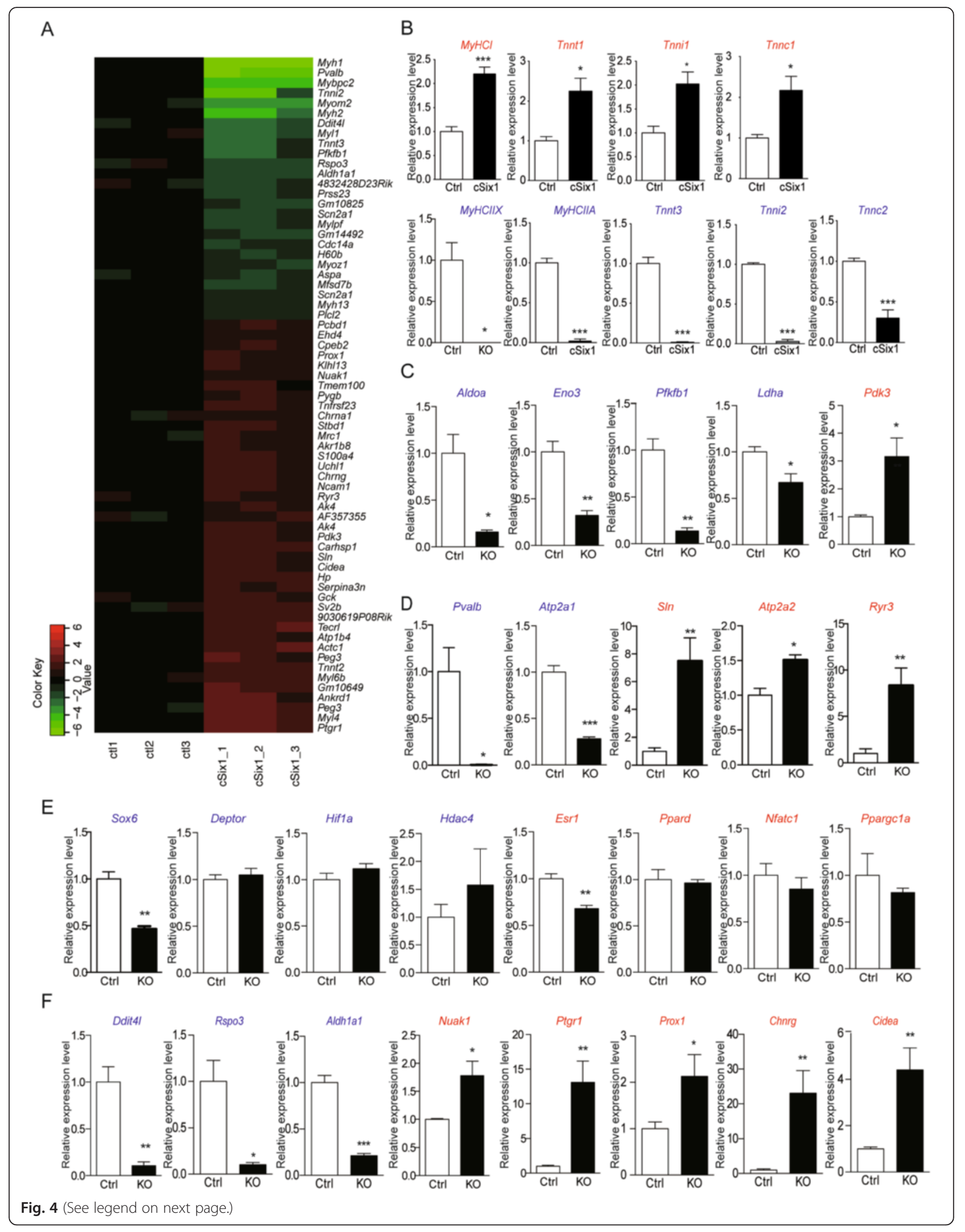


(See figure on previous page.)

Fig. 4 Affymetrix microarray analysis in soleus of cSix 1 mice. a Microarray analysis of soleus of 3-month-old cSix 1 KO mice $(n=3)$ and Ctrl mice $(n=3)$ : a heat map of genes significantly upregulated (red) or downregulated (green) by twofold compared with Ctrl mice. b-f mRNA expression levels of sarcomeric genes (b), energy metabolism (c), calcium regulation (d), transcription factors (e), and most down-regulated or up-regulated genes $(\mathbf{f})$ in soleus of 3 -month-old $c$ Six $1 \mathrm{KO}$ mice, Ctrl $(n=4), c \operatorname{Six} 1(n=3) .{ }^{*} P<0.05,{ }^{* *} P<0.01,{ }^{* * *} P<0.001$

Additional file 4: Figure S2 and Additional file 5: Figure S3). Aldoa possesses several promoters, and its fast-type one is a known direct target of Six proteins [25, 27]. Musclespecific Aldoa mRNA expression was strongly downregulated in SOL of $c$ Six $1 \mathrm{KO}$ mice (Fig. 4c). We also observed the down-regulation of Slc2a4 (Glut4) and Tbc1d1-involved in Glut4 vesicular traffic [46] - of glycolytic genes (Eno3, Pfkfb1), of muscle Creatine Kinase, of $L d h a$, and $L d h d$ of the $\mathrm{NAD}^{+}$-dependent isocitrate dehydrogenase $I d h 3 a$, of $I d h 1$, the down-regulation of $P d p 1$, an activator of and the up-regulation of $P d k 3$ an inhibitor of pyruvate dehydrogenase activity, and validated by qPCR experiments of their expression (Fig. 4d). No major up- or down-regulation of genes related with oxidative metabolism was detected (Additional file 4: Figure S2), which is consistent with the results of the Western blot analysis showing no major modification of the quantity of the electron transport chain proteins (Fig. 3c).

To investigate potential interaction between Six1 and known fiber-type regulators that may participate downstream of Six 1 to the observed phenotype, we analyzed their expression levels by Affymetrix and qPCR (Fig. 4e and Additional file 4: Figure S2). Sox6 gene, a known repressor of slow sarcomeric genes [22, 24], showed a twofold expression decrease in SOL of $c \operatorname{Six} 1 \mathrm{KO}$ mice (Fig. 4e). This down-regulation may be involved in the up-regulation of the expression of its known slow-type gene targets MyHCI, Tnnt1, Tnnt2, Tnni1, and Tnnc1 [22-24, 47] observed in $c$ Six 1 mutant myofibers. Expression of Esr1 gene (estrogen receptor 1), an activator of the slow/oxidative phenotype in females [48] was decreased in $c \operatorname{Six} 1 \mathrm{KO}$ mice. We tested the expression of Ppargcla and Nfatc1 known transcriptional activators of slow-oxidative genes [1, 2], but found no significant modifications of their expression levels in SOL of $c$ Six 1 mice (Fig. 4e). We were also unable to detect modifications of the expression of mRNA encoding TFAM, PPAR $\beta$, Rev-erb- $\alpha$, or Mef $2 \mathrm{C}$, known transcription factors controlling the slow/oxidative phenotype of adult myofibers (data not shown). Altogether our results indicate that in SOL of adult mice, Six1 controls the expression of genes coding for fast-type sarcomeric and calcium handling proteins, for glycolytic proteins, and for Sox6 a known repressor of slow type sarcomeric genes; absence of Six 1 leading to a myofiber switch toward a slower phenotype. Interestingly, in SOL of $c \operatorname{Six} 1$ KO, we also observed the up-regulation of Prox1 (Fig. 4f), a known repressor of the fast genes Tnnt3, Tnni2,
MyHCIIA, and Myl1, and which may also account for their down-regulation [49].

Among the genes showing the most up- or downregulation in mutant SOL, Affymetrix analysis also revealed a strong reduction of the expression levels of Ddit4l (Redd2) an inhibitor of the mTOR pathway [50], Rspo3 (R-Spondin3) and Aldh1a1 and the increase of the expression level of Nuak1 (NUAK family, SNF1-like kinase, 1), Ptgr1 (Prostaglandin reductase1), Chnry and Chnra1 (Acetylcholin receptor gamma and alpha1), and Cidea (cell death-inducing DNA fragmentation factor, alpha subunit-like effector A), an inhibitor of AMPK [51] (Fig. 4a). We also validated the expression of those genes by qPCR (Fig. 4f).

These results indicate that Six1 has a role to enhance the glycolytic pathway in myofibers of adult SOL through the transcription of genes coding for glycolytic proteins, and may modulate more generally glucose utilization in adult myofibers by modulating the expression of key modulators of glucose flux among which Krebs cycle genes (Additional file 5: Figure S3).

\section{Skeletal muscle-specific Tamoxifen-inducible Six 1 knock- out mice also showed fast-to-slow fiber type transition}

To examine the role of Six 1 in the maintenance of myofibers phenotype in the adult SOL, we bred Six $1^{\text {flox } f l o x}$ mice with transgenic mice expressing Cre-ER ${ }^{\mathrm{T} 2}$ recombinase under the control of the HSA promoter [36] to obtain Six $f^{\text {flox/flox }}$; HSA-Cre-ER ${ }^{T 2}$ conditional inducible knockout mice (hereafter named ciSix 1 KO), to induce Six1 deletion after Tamoxifen injection. Eight-week-old ciSix1 KO mice and their littermate Ctrl were injected with Tamoxifen. One month after Tamoxifen injection, Six 1 mRNA level in ciSix1 KO was reduced by 90\% compared with that in Ctrl mice (Fig. 5a). We further analyzed SOL fiber-type composition by immunohistochemistry (Fig. 5b, c). The percentage of MyHCI positive fiber in ciSix 1 KO mice increased to $90 \%$, and the percentage of MyHCIIA positive fiber in ciSix $1 \mathrm{KO}$ mice decreased to $10 \%$. This result showed that Six 1 is required for the maintenance of MyHCIIA expression in SOL at the adult stage.

To compare the phenotypic consequences of Six 1 deletion in the adult myofibers and during development, mRNA expression levels of genes identified previously were estimated in SOL of ciSix1 KO by qPCR. The expression of fast-type sarcomeric genes (MyHCIIX, $\mathrm{MyH}$ CIIA, Tnnt3, Tnni2, Tnnc2) was also down-regulated 


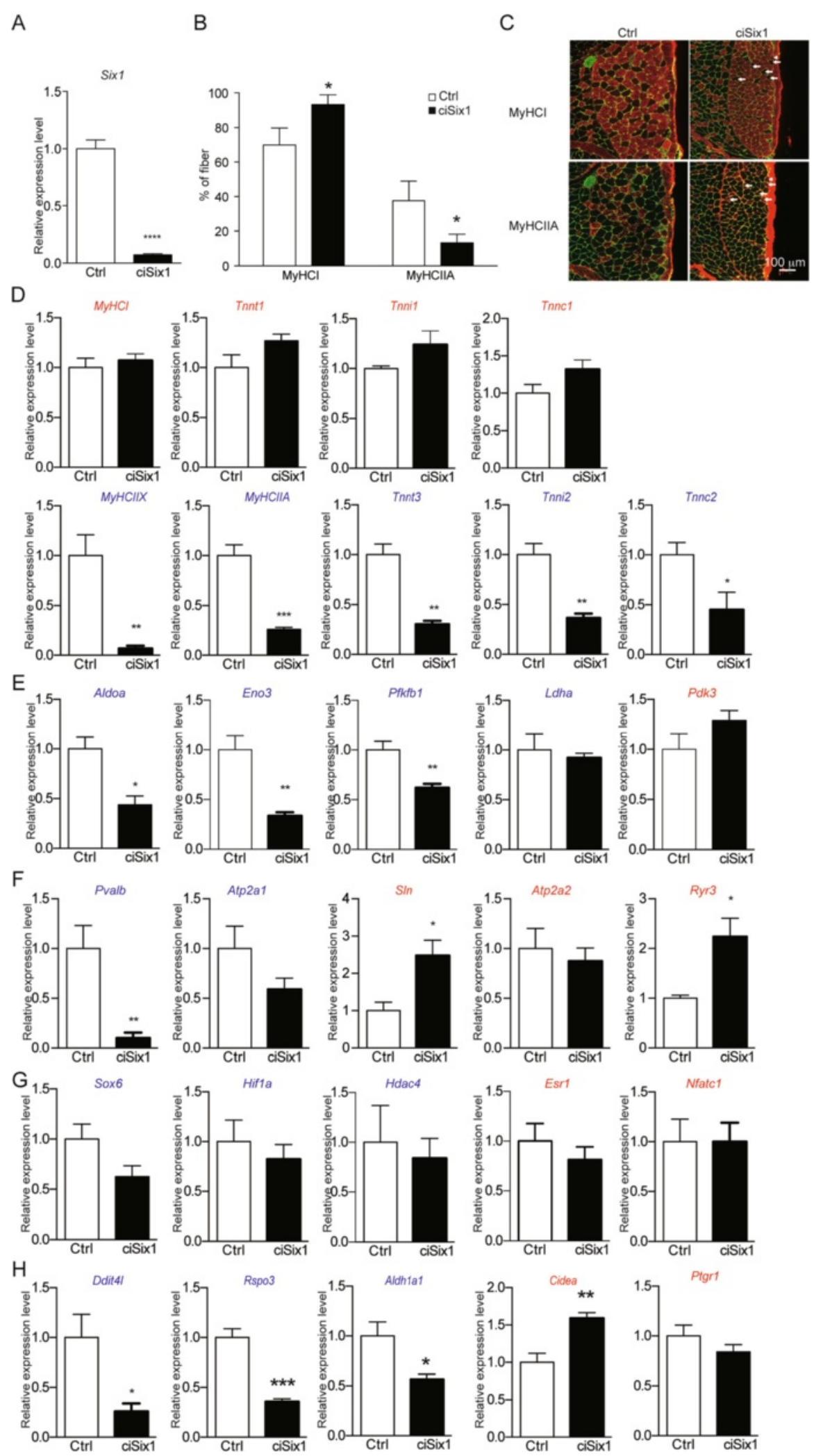

Fig. 5 (See legend on next page.) 
(See figure on previous page.)

Fig. 5 Tamoxifen-induced conditional muscle specific Six 1 knockout reduced fast-type gene expression in soleus. a Six 1 mRNA expression levels in SOL of 3 month-old control (Ctrl, $n=3)$ and ciSix $1 K O(n=4)$ mice 1 month after tamoxifen injection. b Percentage of myofibers expressing $\mathrm{MyHCl}$ or $\mathrm{MyHCIIA}$ in SOL of 3 month-old control $(\mathrm{Ctrl}, n=3)$ and ciSix $1 \mathrm{KO}(n=4)$ mice 1 month after tamoxifen injection. $\mathbf{c}$ Immunostaining of MyHCl (red) and $\mathrm{MyHCIIA} \mathrm{(red)} \mathrm{in} \mathrm{SOL} \mathrm{of} 3$ month-old control and ciSix $1 \mathrm{KO}$ mice 1 month after tamoxifen injection. Arrows indicate fibers expressing MyHCIIA, and an arrow head indicates a fiber expressing both $\mathrm{MyHCl}$ and $\mathrm{MyHCIIA}$ in ciSix1 KO mice. $\mathbf{d}$-g mRNA expression levels of sarcomeric genes (d), energy metabolism (e), calcium regulation (f), transcription factors ( $\mathbf{g})$, and most down-regulated or up-regulated genes (h) in SOL of 3 month-old control $(\mathrm{Ctrl}, n=3)$ and ciSix $1 \mathrm{KO}(n=4)$ mice 1 month after tamoxifen injection. ${ }^{*} P<0.05,{ }^{* *} P<0.01,{ }^{* * *} P<0.001$

(Fig. 5d), consistent with immunohistochemistry results. In contrast, we did not observe a significant upregulation of slow-type sarcomeric genes ( $\mathrm{MyHCI}$, Tnnt1, Tnni1, Tnnc1), that may be related to the absence of Sox6 down regulation (Fig. 5d). For genes controlling glucose metabolism, we observed that the expression level of glycolytic enzymes (Aldoa, Pfkfb1, and Eno3) was down-regulated, and that the expression level of Ldha and Pdk3 was not altered (Fig. 5e). Concerning genes controlling calcium handling, mRNA level of Pvalb was decreased by $90 \%$ compared with that of Ctrl mice, and an increase of Sln and Ryr3 mRNA levels was observed (Fig. 5f). mRNA level of fiber type regulators such as Sox6 was not significantly changed between ciSix1 $\mathrm{KO}$ mice and Ctrl mice (Fig. 5g), contrary to what was observed in $c \operatorname{Six} 1 \mathrm{KO}$. The decreased expression level of Ddit4l, Rspo3, and Aldh1a1, and the increased expression level of Cidea were also observed in the SOL of ciSix1 KO mice (Fig. 5h). These data show that one main function of Six1 in adult SOL could be to activate the expression of a network of fast-glycolytic specific genes among which are MyHCIIA, Aldoa, and Pvalb. The modulation of slow-type genes expression was not observed in the time window of 4 weeks following Six1 deletion, suggesting that it may take more time to completely transdifferentiate fast-MyHCIIA myofibers into slow myofibers.

\section{Pvalb is a direct target of Six 1}

A robust reduction of Pvalb mRNA observed in $c$ Six 1 $K O$ mice and in ciSix $1 K O$ mice led us to test the hypothesis that Pvalb is a direct target of Six1. We analyzed the Pvalb promoter sequence and identified MEF3 regulatory elements. Two MEF3 sites located at $-725 \mathrm{bp}$ (Pvalb MEF3-1) and -148 bp (Pvalb MEF3-2) from the transcription start site of Pvalb were identified (Fig. 6a). Six1 binding at these MEF3 sites was demonstrated in vivo by ChIP experiments with Six1 antibodies on adult fast GP and TA muscles (Fig. 6b) and confirmed for both of these sites by EMSA assays with recombinant Six1 and Six4 proteins (Fig. 6c). We next tested the transcriptional activating potential of these elements in vivo in transient transfection assays. A 748 bp DNA fragment of the Pvalb promoter, including the two identified MEF3 sites, was ligated to pGL3 basic plasmids to generate pGL3-Pvalb constructs. Mutations of the two MEF3 sites were introduced in the promoter sequence, giving rise to Pvalb mut-MEF3-1, Pvalb mut-MEF3-2, and Pvalbmut-MEF3-1/2. Luciferase activity was tested after electroporation of these reporter plasmids in adult TA muscles. The activity of a pGL3-Pvalb was 100 -fold higher than that of the empty pGL3 vector. Luciferase activity was strongly decreased when the MEF3-2 site at -148 was mutated. No further transcriptional decrease of the Pvalb promoter was observed when both MEF3 sites were mutated (Fig. 6d). Altogether, these results demonstrate that Pvalb is a direct target of Six1, and that Six 1 binding to the proximal MEF3 site present in the Pvalb promoter is essential for its transcriptional activity in vivo.

\section{Discussion}

In this study, we analyzed the subcellular distribution of Six1 homeoprotein during postnatal development in adult SOL muscle, and the consequences of Six 1 loss during muscle fiber type specialization. We showed that Six1 proteins accumulated differentially in the myonuclei of adult fast and slow fibers. Absence of Six 1 delayed the transition from embryonic MyHCemb fiber type to adult fast-type MyHCIIA fiber type, leading to a concerted down-regulation of the fast-type program and upregulation of the slow-type program. Transcriptomic analysis of Ctrl and mutant SOL identified a network of down-regulated and up-regulated genes upon Six1 deficiency. Particularly, Six1 is required in the SOL to activate the expression of several fast sarcomeric genes, glycolysis genes, fast-type calcium-handling genes as well as Sox6, a repressor of slow genes. Conversely, upregulated expression was observed in Six 1 mutant SOL for numerous slow sarcomeric genes and for Prox 1 , a repressor of fast genes. We further identified Pvalb, a key player in intracellular $\mathrm{Ca}^{2+}$ buffering, as a direct target of Six1. Altogether our analysis revealed that Six 1 is an essential genetic determinant of fast-type specialization during the post-natal period, and that Six 1 is required in the adult for the maintenance of this phenotype.

\section{Development of the fast-type IIA phenotype in SOL}

Adult mouse SOL is composed of distinct types of myofibers characterized by their contractile and metabolic 


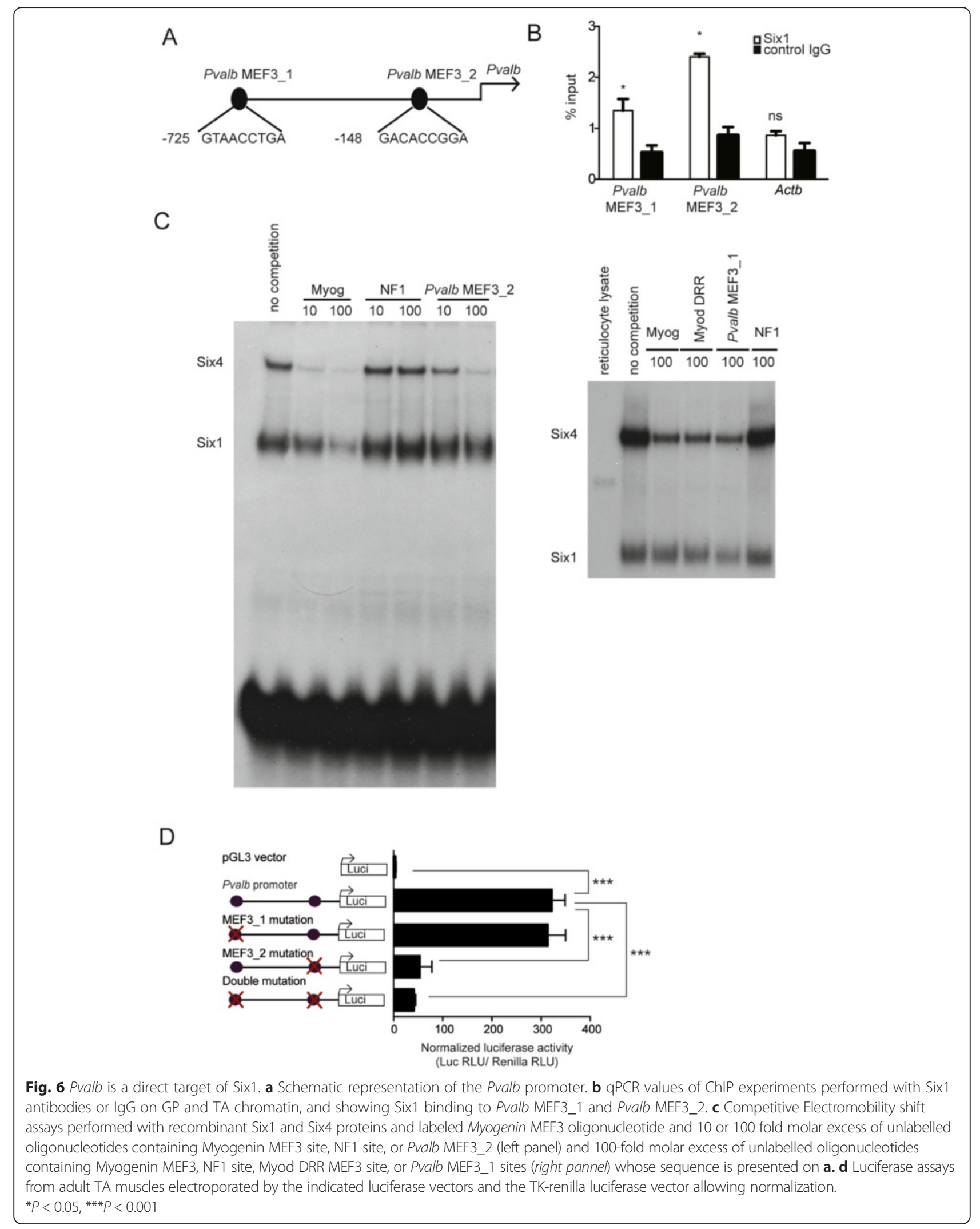


properties and expressing either the slow $\mathrm{M} y \mathrm{HCI}$, the fast MyHCIIA, or, more rarely, the fast MyHCIIX gene [5]. We observed that the Six1 proteins accumulate differentially in adult myonuclei, with a more pronounced enrichment in fast fibers of the GP (Fig. 1) as compared with the fibers of the SOL. However, Six 1 mRNA and total protein levels were found similar between SOL and the fast GP [25]. Altogether, these observations suggest that Six 1 could be sequestered outside of most MyHCI myonuclei, or actively retained in the nuclei of fast-type fibers, and we show that this control takes place during the perinatal period. Nevertheless, in the SOL Six1 proteins coordinate the expression of genes specific of the adult fast phenotype (Mybpc2, Tnni2, Tnnt3, Pvalb, Sox6), most probably in MyHCIIA fibers where these genes are coexpressed with MyHCIIA. Most of those fast-type genes are also down-regulated in fast GP or TA muscles of $c \operatorname{Six} 1$ mutant, as already reported [25], demonstrating that Six 1 acts as a major determinant of fast type gene expression in the different fast fibers subtypes, its absence leading to a "slower phenotype". In the GP and fast tibialis muscles, absence of Six1 leads to the down regulation of MyHCIIB and MyHCIIX and the upregulation of $\mathrm{MyHCI}$ and $\mathrm{MyHCIIA}$ [25], while in the SOL it abrogates MyHCIIX and MyHCIIA expression. To explain this discrepancy one can suggest that the absolute quantity of Six homeoproteins (Six1, Six2, Six4, and Six5) present in the myonucleus tightly controls the expression of the fast $M y h$ genes cluster [52]; high levels being required to activate $M y H C I I B$, while lower levels would favor MyHCIIA expression. In fast muscles, absence of Six1 would lead to decrease the overall Six level which would nevertheless remain sufficient to activate MyHCIIA [25], while in the SOL the threshold of Six proteins reached in absence of Six1 would not allow to maintain MyHCIIA expression. Quantification of nuclear Six2, Six4, and Six 5 proteins remaining in SOL and GP muscles of Six 1 mutant mice may help testing this hypothesis. Alternatively, other yet unidentified specific transcription factors may compensate Six 1 loss in fast TA and GP muscles allowing MyHCIIA expression observed in Six1cKO, while their absence in SOL would preclude MyHCIIA expression. Identification of the transcription factor machinery present specifically in MyHCIIA, MyHCIIX and MyHCIIB myofibers and responsible for the expression of a single fast $M y h$ gene at the locus remains to be established. We also observed that in $c$ Six 1 mutant SOL, SDH and GPDH activities are decreased, and that many genes coding for glycolytic proteins are downregulated. More particularly, we identified a decrease of Phosphofructo-kinase, of AldolaseA, of Glyceraldehyde-3-phosphate dehydrogenase and of Enolase 3 mRNAs, arguing for a decreased glucose use in cSix1 mutant SOL. Furthermore, we observed an increase of $P d k 3$ and a decrease of $P d p 1$ mRNAs, which should lead to a decrease of Pyruvate Dehydrogenase activity and consequently a decrease of acetyl CoA production. Last, expression of Isocitrate dehydrogenase 3, higher in MyHCIIA and MyHCIIX myofibers [5], is also decreased in mutant SOL. Altogether these results suggest a concerted control of sarcomeric genes and of genes controlling glucose metabolism by Six 1 homeoproteins.

We observed that 3-week-old animals show already a lower accumulation of Six1 in myonuclei of the SOL as compared to the fast gastrocnemius. Mechanisms underlying Six1 nucleocytoplasmic shuttle and specific accumulation in perinatal and adult fast myofibers remain to be identified. At birth, SOL myofibers express the embryonic $\mathrm{MyHCemb}$, neonatal and the slow $\mathrm{MyHCI}$ genes [53]. Fast MyHCIIA is detected at the mRNA level at post-natal stages, and its expression increases during the 3 weeks after birth at the expense of MyHCemb and $\mathrm{MyHCneo,} \mathrm{whose} \mathrm{expression} \mathrm{declines} \mathrm{with} \mathrm{neuromuscu-}$ lar junction (NMJ) maturation [2]. We observed that in cSix1 SOL the transition from MyHCemb to MyHCIIA is impaired, and that three weeks old mutant animals still express $\mathrm{MyHCemb}$ in the SOL, showing the requirement of Six 1 for the transition from embryonic Myh to adult Myh expression and myofiber specialization.

During post-natal development, three main factors are involved in the emergence of adult myofiber specialization [2] and that may control Six1 accumulation specifically in fast myonuclei.

The first factor involves the influence of slow and fast neuromuscular junctions. Myofibers are still polyinnervated at birth in the SOL, and retraction of polyinnervation only takes place in the first weeks after birth giving rise to slow-twitch fatigue resistant and fast-twitch fatigue resistant alpha motoneurons on slow/MyHCI and fast/MyHCIIA myofibers, respectively [54, 55]. During this period, in the rodents' SOL, the expression of embryonic and neonatal $M y h$ is replaced by the expression of either adult $\mathrm{MyHCI}$ or MyHCIIA [53, 56]. Accordingly, low Six1 nuclear accumulation in MyHCI myofibers may be the consequence of slow motoneurons activity. The main second messenger of slow tonic firing in the myofiber is the $\mathrm{Ca}^{++}$concentration flux that modulates Calcineurin and CaMK activities [57]. Calcineurin phosphatase activity then controls the subcellular localization of NFATc transcription factors [14, 58]. Calcineurin signaling from the perinatal period on appears to be essential for fiber-type specialization, as supported by experiments in transgenic animals showing that its blockade by forced MCIP1 expression impairs slow fibers specialization [59].

In SOL of Myod1-MCIP1 transgenic mice, Myoglobin expression is not reduced, while the expression of $\mathrm{MyHCI}$ is downregulated from day 7 and is undetected from day 
14 [59]. We did not detect in $c$ Six $1 K O$ or ciSix1 SOL modification of the expression of Myoglobin, suggesting that in both cases mutant myofibers are not completely reprogrammed. Transient Six1 expression in perinatal myofibers of cSix1 SOL may explain why MyHCIIA is transiently expressed in the perinatal period, until the end of SC accretion that takes place in the first 3 weeks post natal [39], and of regular Six1 positive nuclei supply. Thus, the incomplete reprogramming observed in adult cSix 1 mutant SOL may be the consequence of accretion of new satellite cells into the growing post-natal fast MyHCIIA myofibers that provides transiently a genetically or epigenetically programmed fast phenotype that impairs their total reprogramming.

It is known that $\mathrm{MyHCI}$ expression during the perinatal period as well as in the adult is nerve-dependent [60-62]. Accordingly, all cSix1 mutant SOL myofibers that express only $\mathrm{MyHCI}$ should be innervated by slow motoneurons. We observed a strong decrease of the expression of R-Spondin3 (Rspo3) in cSix1 mutant myofibers. R-spondins are secreted proteins known to enhance $W n t / \beta$-catenin signaling [63] which is a major actor of neuromuscular jonctions (NMJ) [64]. Mice mutant for $\beta$-catenin in the myofiber show presynaptic differentiation defects [65]. Whether a Rspo3/ $\beta$-catenin pathway controlled by Six 1 may favor specific stabilization of fast-twitch fatigue resistant alpha motoneuron on future MyHCIIA myofibers is an interesting issue that remains to be tested. Related to this observation, we noted the increase of the expression of Chnry and Chnral, suggesting NMJ remodeling in $c \operatorname{Six} 1 \mathrm{SOL}$.

A second important mechanism involved in fast myofiber specialization during the perinatal period concerns the influence of thyroid hormone [66, 67]. In agreement, hypothyroidic animals show delayed fast Myh transition and prolonged MyHCemb expression [68], a phenotype also found in cSix 1 mutant SOL. Affymetrix transcriptomic analysis did not reveal a link between the presence of Six1 in SOL and the level of thyroid receptors (TR) or TR co-factors expression. This suggesting that the absence of fast phenotype acquisition in $c$ Six 1 mutant SOL is not due to a decreased expression of $T R$, although more detailed analysis of the expression of miR-133a1, a direct TR target gene in adult skeletal muscle involved in the control of TEAD1 expression [67], remains to be performed. While Six 1 does not control $T R$ expression in SOL, the possibility that nuclear Six1 accumulation in fast myofibers could be controlled by the thyroid hormone axis remains an interesting possibility.

A third factor that may participate in myofiber specialization involves intrinsic cell autonomous differences in distinct population of myogenic progenitors leading to myofibers heterogeneity. It is suspected that adult satellite cells associated with slow or fast muscles have intrinsic different genetic properties, although extrinsic factors arising in extracellular matrix or from muscle position and usage in the limb has not been completely excluded [69]. It is therefore tempting to speculate that satellite cells (SC), associated with future MyHCIIA and MyHCI myofibers in the SOL, accreted in the growing myofiber during post-natal development possess specific heritable properties. As myonuclei present in the SOL at 3 weeks show lower Six 1 accumulation as compared with myonuclei of the GP, this may suggest that perinatal SC accreted in growing SOL and GP myofibers express different level of Six1, depending of their localization in the niche of $\mathrm{MyHCI}$ or subtypes of fast Myh myofibers. It would thus be interesting to test Six1 expression level in GP and SOL associated SC to confirm this hypothesis.

\section{Fast MyHCIIA expression in adult soleus}

In the mammalian genome, a number of genes are organized in clusters such as the $\beta$-globin [70], the Hox [71], and the fast $M y h$ cluster [52]. Within these clusters, the precise order of the genes allows their sequential expression through shared enhancers. We showed previously that in adult fast TA and GP muscles Six1 is bound on a central enhancer located at the Myh fast locus between MyHCemb and MyHCIIA, and that it controls the expression of MyHCIIB [25]. We show here that in addition Six1 is essential for efficient fiber type shift from MyHCemb to MyHCIIA in SOL muscles during postnatal development (Fig. 2). The above mentioned fast $M y h$ enhancer is able to activate the transcription of the MyHCIIX, MyHCIIA and MyHCIIB genes and may control higher order chromatin conformation at the locus to allow a single fast $M y h$ gene to be expressed in all myonuclei of each fiber [25]. MyHCIIA activation during the perinatal period in SOL may also depend on this enhancer, and on its own promoter elements known also to interact with Six1 [25, 72].

It will be of major interest to unravel the mechanisms presiding the choice of the expression of a single fast Myh gene at the locus in a given myofiber during the perinatal period, its coordinated associated metabolic specialization and the involvement of Six 1 in this matter. In the case of the $\beta$-globin, an LCR localized upstream of Globin genes controls the spatiotemporal and sequential expression of each gene at the locus. The transcription factor Sox6 binds to each private Globin regulatory elements and coordinates the interactions with the LCR through chromatin conformation modification [73, 74]. Interestingly, Sox6 also binds intergenic regions of $M y h$ locus in C2 myotubes [22, 24]. An interesting hypothesis would thus be that mechanisms similar to those controlling the $\beta$-globin locus could act at the Myh locus with Six 1 and Sox6 cooperating to orchestrate the spatiotemporal 
expression of the Myh fast genes. Sox6 mRNA is expressed in adult fast type muscles, not in slow type muscles [22], and skeletal muscle specific Sox6 knockout mice showed fiber type transition from fast to slow. cSix $1 \mathrm{KO}$ SOL mice have an increased expression of slow type genes that may be partly the consequence of decreased expression of Sox6 mRNA level observed. We have shown previously that Six homeoproteins also control the nuclear accumulation of Sox6 in fetal muscle [29], and we cannot exclude that in $c \operatorname{Six} 1 \mathrm{KO}$ this is not also the case. It would be interesting to determine whether Six1 is relocalized ouside of the nucleus in adult Sox6 mutant myofibers since all myofibers in SOL of Sox6 mutant mice express $M y H C I$ [22, 24] and that in transgenic mice overexpressing Sox6 the expression of slow type genes like $\mathrm{MyHCI}$ and Tnni1 is down regulated [75]. The consequence of Sox6 down regulation observed in cSix1 SOL may also be responsible of Prox1 up regulation. Prox1 is a known repressor of fast muscle gene expression in Zebrafish lying downstream of Sox6 [76] and its deletion in mouse leads to increased expression of fast MyHCIIA, Tnni2, and Tnnt3 genes in SOL [49]. Analysis of the consequences of Prox 1 knock down in $c$ Six 1 SOL would allow to test its involvement in the down regulation of MyHCIIA, Tnni2, and Tnnt3.

\section{Six genes redundancy in adult myofibers}

In our study, HSA-CREert2 recombinase induced deletion of Six 1 in 2 months adult myofibers led to a switch toward a slow phenotype within 4 weeks following Six 1 deletion. This inducible switch was characterized by the decreased expression of MyHCIIX, MyHCIIA, Pvalb, AldoA, and Eno3 and an increased number of MyHCI positive myofibers. In this model, the up-regulation of slow-type muscle genes 4 weeks after Six 1 deletion was less obvious than observed in HSA-CRE animals, possibly because in this paradigm the expression of Sox6, which inhibits a battery of slow muscle genes, is faintly down-regulated. It is possible that during this time period, Six 1 direct targets are efficiently down-regulated, while the up-regulation of slow-type genes might require other modifications such as a switch from fast to slow innervation, and/or decrease of Sox6 expression. Furthermore, the nuclear level of Six 4 and Six 5 homeoproteins, both expressed in adult myofibers, might be higher in SOL of ciSix1 than in cSix1. In adult muscles, the Six4-Baf60c transcription complex controls Deptor expression and transgenic animals with muscle-specific forced expression of Deptor show a switch from oxidative to glycolytic metabolism and are protected from diet-induced insulin resistance [77]. In cSix1 mutant SOL, the level of Deptor mRNA is unchanged, suggesting that the specific Six4/Deptor genetic axis, if maintained in $c$ Six 1 mutant SOL, is sufficient to maintain the level of expression of genes coding for proteins of the glycolytic pathway. cSix1 SOL presents a severe decrease of GPDH enzymatic activity, which may be correlated to a decreased expression of Gpd1 in mutant myofibers. Whether further decreased Six activity by combining Six 1 and Six4 loss in adult myofibers would lead to increased defects of glycolytic flux remains to be evaluated.

Pvalb is a calcium binding protein responsible for fast calcium concentration decrease and relaxation in fast type muscle fiber after excitation. Pvalb knockout mice showed prolonged contraction-relaxation cycle [11] and increased fatigue resistance [44] associated with increased mitochondria composition without major modifications of fiber type specific sarcomeric proteins [43]. We demonstrated that Pvalb is a direct target of Six1 (Fig. 6), but did not observe up regulation of oxidative metabolism components neither at the mRNA level nor at the protein level (Figs. 3, 4, 5, and 6) in $c$ Six 1 mutant SOL, with on the contrary a decreased SDH activity. Recent study with single fiber proteomics revealed that $\mathrm{MyHCI}$ fibers have less mitochondrial proteins and SDH activity compared to MyHCIIA fibers [5]. The loss of MyHCIIA fiber in SOL of Six 1 KO mice might explain the decreased SDH activity observed. In addition, downregulation of Esr1 (estrogen receptor 1), which is known to activate mitochondrial oxidation activity in females [48], was also observed in SOL muscles of cSix1 KO males. These changes may participate in down-regulation of oxidative metabolism in mutant samples (Fig. 3). In that context, down regulation of Esrl could cancel the effect of Pvalb expression decrease in regard of mitochondrial activity.

\section{Conclusions}

We present the evidence that Six1 homeoproteins are required in mouse SOL muscles for the acquisition of the fast MyHCIIA phenotype by controlling MyHCIIA expression and the expression of other fast-type muscle genes among which Sox6, and by controlling efficient glucose utilization through the control of glycolytic and of Krebs cycle genes.

\section{Additional files}

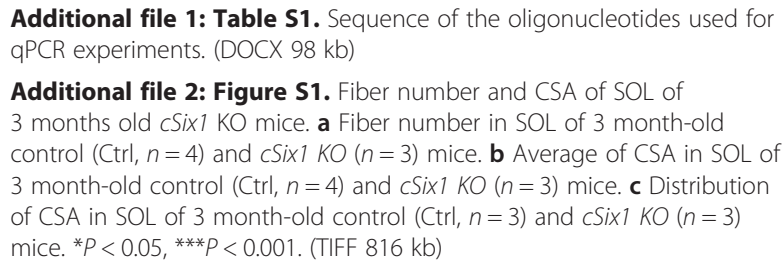

Additional file 1: Table S1. Sequence of the oligonucleotides used for qPCR experiments. (DOCX $98 \mathrm{~kb}$ )

Additional file 2: Figure S1. Fiber number and CSA of SOL of 3 months old cSix $1 \mathrm{KO}$ mice. a Fiber number in SOL of 3 month-old control (Ctrl, $n=4)$ and cSix $K O(n=3)$ mice. b Average of CSA in SOL of 3 month-old control (Ctrl, $n=4)$ and cSix $K O(n=3)$ mice. c Distribution of CSA in SOL of 3 month-old control (Ctrl, $n=3)$ and cSix $1 \mathrm{KO}(n=3)$ mice. ${ }^{*} P<0.05$, ${ }^{* *} P<0.001$. (TIFF $816 \mathrm{~kb}$ )

Additional file 3: Table S2. Affymetrix microarray analysis in SOL of cSix1 mice. (XLS 7368 kb)

Additional file 4: Figure S2. Affymetrix Microarray analysis showing relative gene expression levels of SOL of 3 months old cSix $1 \mathrm{KO}$ mice $(n=3)$ 
compared with those of $\mathrm{Ctrl}$ mice $(n=3)$. A set of genes was selected characteristic of slow/fast sarcomeres, glycolysis, mitochondrial oxidation, transcription factors regulating slow/fast phenotype, Six-homeoproteinsrelated genes. (TIFF $1290 \mathrm{~kb}$ )

Additional file 5: Figure S3. Gene coding for the glycolytic pathway and the Krebs cycle are represented. Genes whose expression is modified in $\mathrm{CSix} \mathrm{KO}$ are indicated as red (up) or green (down). (PDF $281 \mathrm{~kb}$ )

\section{Acknowledgements}

We thank V. Moncollin at ENS Lyon for help with the adult muscle ChIP experiments, the imaging facility at Institute Cochin for technical assistance, the sequencing and genomic platform at Institute Cochin for microarray experiments and F. Dumont and S. Jacques for advice. We Thank Dr. Daniel Metzger for the gift of the HSA-CRE ert2 mouse line. We thank Dr. Sophie Gautron and Dr. Stefano Schiaffino for critical reading of the manuscript and Dr Pascale Bossard for helpful discussions. I.S. is supported by ANR, The Uehara Memorial Foundation and JSPS Postdoctoral Fellowships for Research Abroad. Financial support was provided by the Institut National de la Santé et la Recherche Médicale (INSERM), the "Association Française contre les Myopathies" (AFM), the Centre National de la Recherche Scientifique (CNRS), and the Agence Nationale pour la Recherche (ANR RPV09108KKA). We also acknowledge a contribution to the Institut Cochin animal care facility, made by the Région lle de France.

\section{Authors' contributions}

IS and PM designed the research. IS, MW, MDS, RD, AG, SD, and PM performed the experiments. IS, MS, and PM analyzed the data. IS, KS, and PM wrote the manuscript. All authors approved the final manuscript.

\section{Competing interests}

The authors declare that they have no competing interests.

\section{Author details}

${ }^{1}$ INSERM U1016, Institut Cochin, Paris 75014, France. ${ }^{2}$ CNRS UMR 8104, Paris 75014, France. ${ }^{3}$ Université Paris Descartes, Sorbonne Paris Cité, Paris 75014 , France. ${ }^{4}$ Division of Integrative Pathophysiology, Proteo-Science Center, Graduate School of Medicine, Ehime University, Ehime, Japan. ${ }^{5}$ Laboratoire de Physique Statistique, CNRS, Université P. et M. Curie, Université D. Diderot, École Normale Supérieure, Paris 75005, France. ${ }^{6}$ Nestlé Institute of Health Sciences SA, EPFL Innovation Park, Lausanne, Switzerland.

Received: 27 April 2016 Accepted: 16 August 2016

Published online: 05 September 2016

\section{References}

1. Gundersen K. Excitation-transcription coupling in skeletal muscle: the molecular pathways of exercise. Biol Rev Camb Philos Soc. 2011:86(3):564-600.

2. Schiaffino S, Reggiani C. Fiber types in mammalian skeletal muscles. Physiol Rev. 2011;91(4):1447-531.

3. Braun T, Gautel M. Transcriptional mechanisms regulating skeletal muscle differentiation, growth and homeostasis. Nat Rev Mol Cell Biol. 2011;12(6):349-61.

4. Greising SM, Gransee HM, Mantilla CB, Sieck GC. Systems biology of skeletal muscle: fiber type as an organizing principle. Wiley Interdiscip Rev Syst Biol Med. 2012;4(5):457-73

5. Murgia M, Nagaraj N, Deshmukh AS, Zeiler M, Cancellara P, Moretti I, Reggiani C, Schiaffino S, Mann M. Single muscle fiber proteomics reveals unexpected mitochondrial specialization. EMBO Rep. 2015;16(3):387-95.

6. Babu GJ, Bhupathy P, Timofeyev V, Petrashevskaya NN, Reiser PJ, Chiamvimonvat N, Periasamy M. Ablation of sarcolipin enhances sarcoplasmic reticulum calcium transport and atrial contractility. Proc Natl Acad Sci U S A. 2007;104(45):17867-72.

7. Tupling AR, Asahi M, MacLennan DH. Sarcolipin overexpression in rat slow twitch muscle inhibits sarcoplasmic reticulum Ca2+ uptake and impairs contractile function. J Biol Chem. 2002;277(47):44740-6.

8. Winther AM, Bublitz M, Karlsen JL, Moller JV, Hansen JB, Nissen P, Buch-Pedersen MJ. The sarcolipin-bound calcium pump stabilizes calcium sites exposed to the cytoplasm. Nature. 2013;495(7440):265-9.
9. Toyoshima C, Iwasawa S, Ogawa H, Hirata A, Tsueda J, Inesi G. Crystal structures of the calcium pump and sarcolipin in the Mg2 +-bound E1 state. Nature. 2013;495(7440):260-4.

10. Anderson DM, Anderson KM, Chang CL, Makarewich CA, Nelson BR, McAnally JR, Kasaragod P, Shelton JM, Liou J, Bassel-Duby R, et al. A micropeptide encoded by a putative long noncoding RNA regulates muscle performance. Cell. 2015;160(4):595-606.

11. Schwaller B, Dick J, Dhoot G, Carroll S, Vrbova G, Nicotera P, Pette D, Wyss A, Bluethmann $\mathrm{H}$, Hunziker W, et al. Prolonged contraction-relaxation cycle of fast-twitch muscles in parvalbumin knockout mice. Am J Physiol. 1999;276(2 Pt 1):C395-403.

12. Rao A, Luo C, Hogan PG. Transcription factors of the NFAT family: regulation and function. Annu Rev Immunol. 1997:15:707-47.

13. Naya FJ, Mercer B, Shelton J, Richardson JA, Williams RS, Olson EN. Stimulation of slow skeletal muscle fiber gene expression by calcineurin in vivo. J Biol Chem. 2000;275(7):4545-8

14. Tothova J, Blaauw B, Pallafacchina G, Rudolf R, Argentini C, Reggiani C, Schiaffino S. NFATC1 nucleocytoplasmic shuttling is controlled by nerve activity in skeletal muscle. J Cell Sci. 2006;119(Pt 8):1604-11.

15. Potthoff MJ, Wu H, Arnold MA, Shelton JM, Backs J, McAnally J, Richardson JA, Bassel-Duby R, Olson EN. Histone deacetylase degradation and MEF2 activation promote the formation of slow-twitch myofibers. J Clin Invest. 2007;117(9):2459-67.

16. Summermatter S, Santos G, Perez-Schindler J, Handschin C. Skeletal muscle PGC-1alpha controls whole-body lactate homeostasis through estrogenrelated receptor alpha-dependent activation of $\mathrm{LDH} B$ and repression of LDH A. Proc Natl Acad Sci U S A. 2013;110(21):8738-43.

17. Egan B, Zierath JR. Exercise metabolism and the molecular regulation of skeletal muscle adaptation. Cell Metab. 2013;17(2):162-84.

18. Gali Ramamoorthy T, Laverny G, Schlagowski Al, Zoll J, Messaddeq N, Bornert JM, Panza S, Ferry A, Geny B, Metzger D. The transcriptional coregulator PGC-1beta controls mitochondrial function and anti-oxidant defence in skeletal muscles. Nat Commun. 2015;6:10210.

19. Rowe GC, Patten IS, Zsengeller ZK, El-Khoury R, Okutsu M, Bampoh S, Koulisis N, Farrell C, Hirshman MF, Yan Z, et al. Disconnecting mitochondrial content from respiratory chain capacity in PGC-1-deficient skeletal muscle. Cell Rep. 2013;3(5):1449-56.

20. Schuler M, Ali F, Chambon C, Duteil D, Bornert JM, Tardivel A, Desvergne B, Wahli W, Chambon P, Metzger D. PGC1alpha expression is controlled in skeletal muscles by PPARbeta, whose ablation results in fiber-type switching, obesity, and type 2 diabetes. Cell Metab. 2006;4(5):407-14.

21. Lunde IG, Ekmark M, Rana ZA, Buonanno A, Gundersen K. PPARdelta expression is influenced by muscle activity and induces slow muscle properties in adult rat muscles after somatic gene transfer. J Physiol. 2007; 582(Pt 3):1277-87.

22. Quiat D, Voelker KA, Pei J, Grishin NV, Grange RW, Bassel-Duby R, Olson EN. Concerted regulation of myofiber-specific gene expression and muscle performance by the transcriptional repressor Sox6. Proc Natl Acad Sci U S A. 2011;108(25):10196-201.

23. Hagiwara N, Yeh M, Liu A. Sox6 is required for normal fiber type differentiation of fetal skeletal muscle in mice. Dev Dyn. 2007;236(8):2062-76.

24. An Cl, Dong Y, Hagiwara N. Genome-wide mapping of Sox6 binding sites in skeletal muscle reveals both direct and indirect regulation of muscle terminal differentiation by Sox6. BMC Dev Biol. 2011;11:59.

25. Sakakibara I, Santolini M, Ferry A, Hakim V, Maire P. Six homeoproteins and linc-RNA at the fast MYH locus lock fast myofiber terminal phenotype. PLoS Genet. 2014;10(5):e1004386.

26. Ekmark M, Rana ZA, Stewart G, Hardie DG, Gundersen K. De-phosphorylation of MyoD is linking nerve-evoked activity to fast myosin heavy chain expression in rodent adult skeletal muscle. J Physiol. 2007;584(Pt 2):637-50.

27. Grifone R, Laclef C, Spitz F, Lopez S, Demignon J, Guidotti JE, Kawakami K Xu PX, Kelly R, Petrof BJ, et al. Six1 and Eya1 expression can reprogram adult muscle from the slow-twitch phenotype into the fast-twitch phenotype. Mol Cell Biol. 2004;24(14):6253-67.

28. Mason SD, Howlett RA, Kim MJ, Olfert IM, Hogan MC, McNulty W, Hickey RP Wagner PD, Kahn CR, Giordano FJ, et al. Loss of skeletal muscle HIF-1alpha results in altered exercise endurance. PLoS Biol. 2004;2(10):e288.

29. Richard AF, Demignon J, Sakakibara I, Pujol J, Favier M, Strochlic L, Le Grand F, Sgarioto N, Guernec A, Schmitt A, et al. Genesis of muscle f iber-type diversity during mouse embryogenesis relies on Six 1 and Six4 gene expression. Dev Biol. 2011;359(2):303-20. 
30. Vincent SD, Mayeuf A, Niro C, Saitou M, Buckingham M. Non conservation of function for the evolutionarily conserved prdm1 protein in the control of the slow twitch myogenic program in the mouse embryo. Mol Biol Evol. 2012;29(10):3181-91.

31. Grifone R, Demignon J, Houbron C, Souil E, Niro C, Seller MJ, Hamard G, Maire P. Six 1 and Six4 homeoproteins are required for Pax3 and Mrf expression during myogenesis in the mouse embryo. Development. 2005; 132(9):2235-49.

32. Relaix F, Demignon J, Laclef C, Pujol J, Santolini M, Niro C, Lagha M, Rocancourt D, Buckingham M, Maire P. Six homeoproteins directly activate Myod expression in the gene regulatory networks that control early myogenesis. PLoS Genet. 2013;9(4):e1003425.

33. Liu Y, Chu A, Chakroun I, Islam U, Blais A. Cooperation between myogenic regulatory factors and SIX family transcription factors is important for myoblast differentiation. Nucleic Acids Res. 2010;38(20):6857-71.

34. Buckingham M, Rigby PW. Gene regulatory networks and transcriptional mechanisms that control myogenesis. Dev Cell. 2014;28(3):225-38.

35. Niro C, Demignon J, Vincent S, Liu Y, Giordani J, Sgarioto N, Favier M, Guillet-Deniau I, Blais A, Maire P. Six1 and Six4 gene expression is necessary to activate the fast-type muscle gene program in the mouse primary myotome. Dev Biol. 2010;338(2):168-82.

36. Schuler M, Ali F, Metzger E, Chambon P, Metzger D. Temporally controlled targeted somatic mutagenesis in skeletal muscles of the mouse. Genesis. 2005;41(4):165-70

37. Hallauer $\mathrm{PL}$, Hastings KE. Coregulation of fast contractile protein transgene and glycolytic enzyme expression in mouse skeletal muscle. Am J Physiol Cell Physiol. 2002;282(1):C113-124.

38. Giordani J, Bajard L, Demignon J, Daubas P, Buckingham M, Maire P. Six proteins regulate the activation of Myf5 expression in embryonic mouse limbs. Proc Natl Acad Sci U S A. 2007;104(27):11310-5.

39. White RB, Bierinx AS, Gnocchi VF, Zammit PS. Dynamics of muscle fibre growth during postnatal mouse development. BMC Dev Biol. 2010;10:21.

40. Yajima H, Motohashi N, Ono Y, Sato S, Ikeda K, Masuda S, Yada E, Kanesaki $H$, Miyagoe-Suzuki $Y$, Takeda S, et al. Six family genes control the proliferation and differentiation of muscle satellite cells. Exp Cell Res. 2010; 316(17):2932-44

41. Le Grand F, Grifone R, Mourikis P, Houbron C, Gigaud C, Pujol J, Maillet M, Pages $G$, Rudnicki $M$, Tajbakhsh S, et al. Six1 regulates stem cell repair potential and self-renewal during skeletal muscle regeneration. J Cell Biol. 2012;198(5):815-32.

42. Liu Y, Chakroun I, Yang D, Horner E, Liang J, Aziz A, Chu A, De Repentigny $Y$, Dilworth FJ, Kothary $R$, et al. Six1 regulates MyoD expression in adult muscle progenitor cells. PLoS One. 2013;8(6):e67762.

43. Racay $P$, Gregory P, Schwaller B. Parvalbumin deficiency in fast-twitch muscles leads to increased 'slow-twitch type' mitochondria, but does not affect the expression of fiber specific proteins. FEBS J. 2006;273(1):96-108.

44. Chen G, Carroll S, Racay P, Dick J, Pette D, Traub I, Vrbova G, Eggli P, Celio $M$, Schwaller B. Deficiency in parvalbumin increases fatigue resistance in fast-twitch muscle and upregulates mitochondria. Am J Physiol Cell Physiol. 2001;281(1):C114-122.

45. Ducreux S, Gregory P, Schwaller B. Inverse regulation of the cytosolic $\mathrm{Ca}(2)(+)$ buffer parvalbumin and mitochondrial volume in muscle cells via SIRT1/PGC-1alpha axis. PLoS One. 2012;7(9):e44837.

46. Sakamoto K, Holman GD. Emerging role for AS160/TBC1D4 and TBC1D1 in the regulation of GLUT4 traffic. Am J Physiol Endocrinol Metab. 2008;295(1):E29-37.

47. Hagiwara N, Ma B, Ly A. Slow and fast fiber isoform gene expression is systematically altered in skeletal muscle of the Sox6 mutant, p100H. Dev Dyn. 2005;234(2):301-11.

48. Ribas V, Drew BG, Zhou Z, Phun J, Kalajian NY, Soleymani T, Daraei P, Widjaja K, Wanagat J, de Aguiar Vallim TQ, et al. Skeletal muscle action of estrogen receptor alpha is critical for the maintenance of mitochondrial function and metabolic homeostasis in females. Sci Transl Med. 2016;8(334):334ra354.

49. Petchey LK, Risebro CA, Vieira JM, Roberts T, Bryson JB, Greensmith L, Lythgoe MF, Riley PR. Loss of Prox1 in striated muscle causes slow to fast skeletal muscle fiber conversion and dilated cardiomyopathy. Proc Natl Acad Sci U S A. 2014;111(26):9515-20.

50. Miyazaki M, Esser KA. Cellular mechanisms regulating protein synthesis and skeletal muscle hypertrophy in animals. J Appl Physiol (1985). 2009;106(4):1367-73.

51. Qi J, Gong J, Zhao T, Zhao J, Lam P, Ye J, Li JZ, Wu J, Zhou HM, Li P. Downregulation of AMP-activated protein kinase by Cidea-mediated ubiquitination and degradation in brown adipose tissue. EMBO J. 2008; 27(11):1537-48.

52. Shrager JB, Desjardins PR, Burkman JM, Konig SK, Stewart SK, Su L, Shah MC, Bricklin E, Tewari M, Hoffman R, et al. Human skeletal myosin heavy chain genes are tightly linked in the order embryonic-Ila-IId/x-ILb-perinatalextraocular. J Muscle Res Cell Motil. 2000;21(4):345-55.

53. Agbulut $O$, Noirez P, Beaumont F, Butler-Browne G. Myosin heavy chain isoforms in postnatal muscle development of mice. Biol Cell. 2003:95(6): 399-406.

54. Slater CR. Postnatal maturation of nerve-muscle junctions in hindlimb muscles of the mouse. Dev Biol. 1982;94(1):11-22.

55. Kanning KC, Kaplan A, Henderson CE. Motor neuron diversity in development and disease. Annu Rev Neurosci. 2010:33:409-40.

56. Butler-Browne GS, Whalen RG. Myosin isozyme transitions occurring during the postnatal development of the rat soleus muscle. Dev Biol. 1984;102(2):324-34

57. Olson EN, Williams RS. Remodeling muscles with calcineurin. Bioessays. 2000;22(6):510-9.

58. Calabria E, Ciciliot S, Moretti I, Garcia M, Picard A, Dyar KA, Pallafacchina G, Tothova J, Schiaffino S, Murgia M. NFAT isoforms control activity-dependent muscle fiber type specification. Proc Natl Acad Sci U S A. 2009:106(32): 13335-40.

59. Rybkin II OM, Copeland V, Czubryt MP, Shelton JM, van Rooij E, Richardson $J A$, Hill JA, De Windt $L$, Bassel-Duby $R$, et al. Calcineurin is necessary for the maintenance but not embryonic development of slow muscle fibers. Mol Cell Biol. 2005;25(15):6629-38.

60. Jolesz F, Sreter FA. Development, innervation, and activity-pattern induced changes in skeletal muscle. Annu Rev Physiol. 1981;43:531-52.

61. Salmons S, Henriksson J. The adaptive response of skeletal muscle to increased use. Muscle Nerve. 1981:4(2):94-105.

62. Murgia M, Serrano AL, Calabria E, Pallafacchina G, Lomo T, Schiaffino S. Ras is involved in nerve-activity-dependent regulation of muscle genes. Nat Cell Biol. 2000;2(3):142-7.

63. Ohkawara B, Glinka A, Niehrs C. Rspo3 binds syndecan 4 and induces Wnt/ PCP signaling via clathrin-mediated endocytosis to promote morphogenesis. Dev Cell. 2011;20(3):303-14.

64. Strochlic L, Falk J, Goillot E, Sigoillot S, Bourgeois F, Delers P, Rouviere J, Swain A, Castellani V, Schaeffer L, et al. Wnt4 participates in the formation of vertebrate neuromuscular junction. PLoS One. 2012;7(1):e29976.

65. Li XM, Dong XP, Luo SW, Zhang B, Lee DH, Ting AK, Neiswender H, Kim CH, Carpenter-Hyland E, Gao TM, et al. Retrograde regulation of motoneuron differentiation by muscle beta-catenin. Nat Neurosci. 2008;11(3):262-8.

66. Gambke B, Lyons GE, Haselgrove J, Kelly AM, Rubinstein NA. Thyroidal and neural control of myosin transitions during development of rat fast and slow muscles. FEBS Lett. 1983:156(2):335-9.

67. Zhang D, Wang X, Li Y, Zhao L, Lu M, Yao X, Xia H, Wang YC, Liu MF, Jiang J, et al. Thyroid hormone regulates muscle fiber type conversion via miR-133a1. J Cell Biol. 2014;207(6):753-66

68. d'Albis A, Chanoine C, Janmot C, Mira JC, Couteaux R. Muscle-specific response to thyroid hormone of myosin isoform transitions during rat postnatal development. Eur J Biochem. 1990;193(1):155-61.

69. Kalhovde JM, Jerkovic R, Sefland I, Cordonnier C, Calabria E, Schiaffino S. Lomo T. "Fast" and "slow" muscle fibres in hindlimb muscles of adult rats regenerate from intrinsically different satellite cells. J Physiol. 2005; 562(Pt 3):847-57.

70. Palstra RJ, de Laat W, Grosveld F. Beta-globin regulation and long-range interactions. Adv Genet. 2008:61:107-42.

71. Barber BA, Rastegar M. Epigenetic control of Hox genes during neurogenesis, development, and disease. Ann Anat. 2010;192(5):261-74.

72. Hetzler KL, Collins BC, Shanely RA, Sue H, Kostek MC. The homoeobox gene SIX1 alters myosin heavy chain isoform expression in mouse skeletal muscle. Acta Physiol (Oxf). 2014;210(2):415-28.

73. Xu J, Sankaran VG, Ni M, Menne TF, Puram RV, Kim W, Orkin SH. Transcriptional silencing of \{gamma\}-globin by BCL11A involves long-range interactions and cooperation with SOX6. Genes Dev. 2010;24(8):783-98.

74. Yi Z, Cohen-Barak O, Hagiwara N, Kingsley PD, Fuchs DA, Erickson DT, Epner EM, Palis J, Brilliant MH. Sox6 directly silences epsilon globin expression in definitive erythropoiesis. PLoS Genet. 2006:2(2):e14.

75. van Rooij E, Quiat D, Johnson BA, Sutherland LB, Qi X, Richardson JA, Kelm Jr RJ, Olson EN. A family of microRNAs encoded by myosin genes governs myosin expression and muscle performance. Dev Cell. 2009;17(5):662-73. 
76. Jackson HE, Ingham PW. Control of muscle fibre-type diversity during embryonic development: the zebrafish paradigm. Mech Dev. 2013;130(9-10):447-57.

77. Meng ZX, Li S, Wang L, Ko HJ, Lee Y, Jung DY, Okutsu M, Yan Z, Kim JK, Lin JD. Baf60c drives glycolytic metabolism in the muscle and improves systemic glucose homeostasis through Deptor-mediated Akt activation. Nat Med. 2013;19(5):640-5.

Submit your next manuscript to BioMed Central and we will help you at every step:

- We accept pre-submission inquiries

- Our selector tool helps you to find the most relevant journal

- We provide round the clock customer support

- Convenient online submission

- Thorough peer review

- Inclusion in PubMed and all major indexing services

- Maximum visibility for your research

Submit your manuscript at www.biomedcentral.com/submit 